\title{
Divergence En Route to Non-Classical Annonaceous Acetogenins. Synthesis of Pyranicin and Pyragonicin
}

\author{
Daniel Strand, Per-Ola Norrby and Tobias Rein
}

Supporting information 


\section{Table of contents}

General methodology

$\mathrm{S}-3$

Preparation of and analytical data for compounds 18, 82, 19, 86, 22, 27,

$48 \mathrm{~b}, 49 \mathrm{a}, 49 \mathrm{~b}, 50 \mathrm{a}, 50 \mathrm{~b}, 53,54,58,62,59,63,60,64,66,69,83,70$,

76, 84 and 81

$\mathrm{S}-4$

Determination of the relative configuration of the stereocenters

of the THP-rings in $\mathbf{2 9}$ and $\mathbf{2 8 .}$

$S-26$

Procedure for determination of $d r$ of the butenolide

$\mathrm{S}-28$

${ }^{1} \mathrm{H}$ NMR and ${ }^{13} \mathrm{C}$ NMR spectra for compounds $16,18,82,19,29,28$,

48a, 49a, 50a, 52, 53, 54, 58, 62, 59, 63 and 60

$\mathrm{S}-34$

${ }^{1} \mathrm{H}$ NMR and ${ }^{13} \mathrm{C}$ NMR spectra for compounds $64,66,65,69,83,70$,

$71,76,84,1,2,86,22,27,48 b, 49 b, 50 b$ and 81

$S-70$ 
General methodology. All solvents were distilled before use unless otherwise stated. Diethyl ether $\left(\mathrm{Et}_{2} \mathrm{O}\right)$ and tetrahydrofuran $(\mathrm{THF})$ were distilled from sodium/benzophenone under a nitrogen atmosphere. Dichloromethane (DCM), dichloroethane (DCE), toluene and triethylamine $\left(\mathrm{Et}_{3} \mathrm{~N}\right)$ were distilled from $\mathrm{CaH}_{2}$ under a nitrogen atmosphere. All reactions were carried out in oven-dried or flame-dried glassware and under a nitrogen atmosphere unless water was used as a reaction medium. For reactions run in sealed vessels a thick-walled testtube fitted with a screw cap was used. Commercially available compounds were used without further purification unless otherwise indicated. $t$-BuOK was purchased as a stock solution (1 M) solution in THF. Potassium and sodium hexamethyldisilazide (KHMDS, NaHMDS) were purchased as stock solutions ( 0.5 $\mathrm{M}, 0.6 \mathrm{M}$ in toluene respectively) and titrated according to the method of Ireland and Meissner. ${ }^{1}$ 18-crown-6 was recrystallized from anhydrous acetonitrile and dried under vacuum. Neocuproine was sublimated at $120{ }^{\circ} \mathrm{C}, 0.01 \mathrm{mmHg}$. Commercially available compounds were used without further purification unless otherwise indicated. Zinc triflate was purchased fresh and stored in a glovebox. (+/-)-NME was stored in a glovebox freezer. Acrolein dimer was bulb-to-bulb distilled, oven temperature $60{ }^{\circ} \mathrm{C}, 0.15 \mathrm{mmHg}$. LDA was purchased as a stock solution $(2 \mathrm{M})$ in THF/heptane/ethyl benzene. TLC analyses were performed on aluminium-backed $\mathrm{F}_{254}$ silica gel plates, using UV and a solution of 5\% phosphomolybdic acid in ethanol for visualisation. Flash chromatography was performed as described by Still and coworkers ${ }^{2}$ using silica gel 60 (40-63 $\mu \mathrm{m})$. Proton $\left({ }^{1} \mathrm{H}\right)$ and carbon $\left({ }^{13} \mathrm{C}\right)$ NMR spectra were recorded on a 400 or $500 \mathrm{MHz}$ instrument using the residual signals from $\mathrm{CHCl}_{3}, \delta 7.26 \mathrm{ppm}$ and $\delta 77.0 \mathrm{ppm}$, as internal references for ${ }^{1} \mathrm{H}$ and ${ }^{13} \mathrm{C}$ respectively. IR-spectra were recorded from $\mathrm{CH}_{2} \mathrm{Cl}_{2}$ films using $\mathrm{NaCl}$ plates. Optical rotations were determined using the sodium-D line (589 nm). 


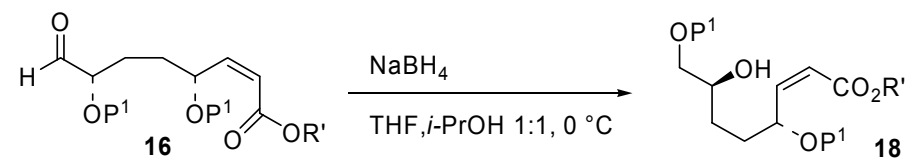

(1S,2R)-2-(1-Methyl-1-phenylethyl)cyclohexyl

$(2 Z, 4 R, 7 S)-4,8-b i s\{[t e r t-$ butyl(diphenyl)silyl]oxy\}-7-hydroxyoct-2-enoate (18). To a solution of aldehyde $\mathbf{1 6}$ (1.86 g, $2.11 \mathrm{mmol})$ in isopropanol/THF $(100 \mathrm{~mL}, 1: 1)$ was added sodium borohydride $(240.1 \mathrm{mg}, 6.35$ $\mathrm{mmol})$ in one portion at $0{ }^{\circ} \mathrm{C}$. After $3 \mathrm{~h}$ the solution was poured into phosphate buffer $(\mathrm{pH} 7)$ and partitioned between EtOAc and phosphate buffer ( $\mathrm{pH}$ 7). The combined organic phases were dried $\left(\mathrm{MgSO}_{4}\right)$, filtered and concentrated in vacuo to afford a crude oil. Purification by flash chromatography (3.13-12.5\% EtOAc/heptane) afforded the secondary alcohol $\mathbf{1 8}$ as a clear oil $(1.289, \mathrm{~g} 70 \%) ;^{3}[\alpha]_{\mathrm{D}}^{23}-19.6\left(\mathrm{c}=0.8, \mathrm{CH}_{2} \mathrm{Cl}_{2}\right)$; IR (film) 3579 (br, s), $3070(\mathrm{w}), 2931(\mathrm{~s}), 2858$ (s), 1719 (s), 1428 (s), 1193 (s), 1110 (s) 700 (s); ${ }^{1} \mathrm{H}$ NMR (MHz, $\left.\mathrm{CDCl}_{3}\right) \delta$ 7.70-7.66 (m, 4H), 7.64-7.60 (m, 2H), 7.60-7.56 (m, 2H), 7.48-7.32 (m, 8H), 7.33-7.25 (m, 4H), 7.25-7.15 (m, 4H), 7.11-7.06 (m, 1H), $5.98(\mathrm{dd}, J=11.6,8.0 \mathrm{~Hz}, 1 \mathrm{H}), 5.40(\mathrm{dd}, J=13.1,6.3 \mathrm{~Hz}, 1 \mathrm{H}), 4.81(\mathrm{dd}, 11.7$, $1.0 \mathrm{~Hz}, 1 \mathrm{H}), 4.59$ (dt, $J=10.3,4.2 \mathrm{~Hz}, 1 \mathrm{H}), 3.73-3.65(\mathrm{~m}, 1 \mathrm{H}), 3.63$ (dd, $J=10.1,3.5 \mathrm{~Hz}, 1 \mathrm{H})$, $3.48(\mathrm{dd}, J=10.0,7.4 \mathrm{~Hz}, 1 \mathrm{H}), 2.60(\mathrm{~d}, J=3.5 \mathrm{~Hz}, 1 \mathrm{H}), 2.00-1.92(\mathrm{~m}, 1 \mathrm{H}), 1.78-0.86(\mathrm{~m}, 12 \mathrm{H})$, 1.17 (s, 3H), 1.14 (s, 3H), 1.09 (s, 9H), 1.05 (s, 9H); ${ }^{13} \mathrm{C} \mathrm{NMR}\left(125 \mathrm{MHz}, \mathrm{CDCl}_{3}\right) \delta 164.9,152.2$, $151.7,136.24,136.21,135.9,134.5,134.4,133.7,133.6,130.2,129.9,129.9,128.3,128.2$, $127.9,127.8,125.7,125.4,118.7,74.6,72.5,70.0,68.4,51.3,40.2,33.9,33.7,28.3,27.6,27.49$, 27.46, 27.3, 26.3, 25.9, 25.1, 19.7; HRMS (FAB, $\mathrm{M}+\mathrm{Na}^{+}$) calcd for $\mathrm{C}_{55} \mathrm{H}_{70} \mathrm{NaO}_{5} \mathrm{Si}_{2}$ 889.4659, found 889.4661 . 


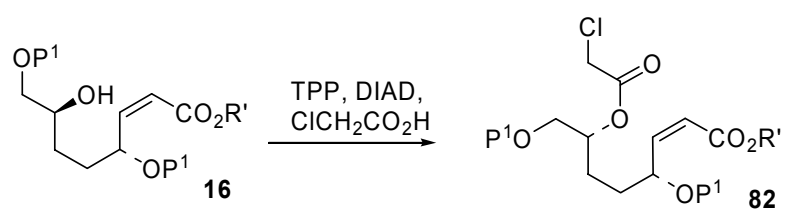

\section{(1S,2R)-2-(1-Methyl-1-phenylethyl)cyclohexyl}

$(2 Z, 4 R, 7 R)-4,8-b i s\{[t e r t-$

butyl(diphenyl)silyl]oxy\}-7-[(chloroacetyl)oxy]oct-2-enoate (82). To a stirred solution of secondary alcohol $18(918 \mathrm{mg}, 1.06 \mathrm{mmol})$, triphenylphosphine (556 mg, $2.12 \mathrm{mmol})$ and chloroacetic acid (200 mg, $2.12 \mathrm{mmol})$ was added DIAD (0.395 mL, $2.01 \mathrm{mmol})$ dropwise over $10 \mathrm{~min}$ at $\mathrm{rt}$. The yellowish mixture turned clear over $5 \mathrm{~min}$ and was stirred for $3 \mathrm{~h}$. The reaction was then quenched by evaporation onto silica. Purification by flash chromatography $(1.56-6.25 \%$ EtOAc/heptane) afforded ester 82 as a clear oil (995 mg, 95\%): $[\alpha]_{\mathrm{D}}^{23}-21.8\left(\mathrm{c}=1.25, \mathrm{CH}_{2} \mathrm{Cl}_{2}\right)$; IR (film) 3070 (w), 2931 (s), 2858 (s), 1762 (m), 1710 (s), 1427 (m), 1187 (s), 1112 (s), 701 (s); ${ }^{1} \mathrm{H}$ NMR (500 MHz, $\left.\mathrm{CDCl}_{3}\right) \delta$ 7.73-7.66 (m, 4H), 7.65-7.56 (m, 4H), 7.49-7.33 (m, 8H), 7.33$7.26(\mathrm{~m}, 4 \mathrm{H}), 7.25-7.17(\mathrm{~m}, 4 \mathrm{H}), 7.16-7.09(\mathrm{~m}, 1 \mathrm{H}), 5.97(\mathrm{dd}, J=11.6,7.9 \mathrm{~Hz}, 1 \mathrm{H}), 5.38(\mathrm{dd}, J=$ 11.9, $5.2 \mathrm{~Hz}, 1 \mathrm{H}), 5.13-5.05(\mathrm{~m}, 1 \mathrm{H}), 4.84(\mathrm{~d}, J=11.6 \mathrm{~Hz}, 1 \mathrm{H}), 4.63(\mathrm{dt}, J=10.3,4.2 \mathrm{~Hz}, 1 \mathrm{H})$, $3.99(\mathrm{dd}, 34.9,14.8 \mathrm{~Hz}, 2 \mathrm{H}), 2.74-3.62(\mathrm{~m}, 2 \mathrm{H}), 2.00(\mathrm{dt}, J=11.1,2.2 \mathrm{~Hz}, 1 \mathrm{H}), 1.86-0.85$ (m, 13H), $1.23(\mathrm{~s}, 3 \mathrm{H}), 1.20(\mathrm{~s}, 3 \mathrm{H}), 1.09(\mathrm{~s}, 9 \mathrm{H}), 1.06(\mathrm{~s}, 9 \mathrm{H}) ;{ }^{13} \mathrm{C} \mathrm{NMR}\left(125 \mathrm{MHz}, \mathrm{CDCl}_{3}\right) \delta 166.8$, $164.3,151.6,151.3,135.75,135.70,135.6,135.5,134.0,133.8,133.2,133.1,129.76,129.72$, $129.59,129.51,127.8,127.7,127.4,127.3,125.3,124.9,118.4,76.5,74.2,69.3,64.9,50.8,41.0$, 39.7, 33.2, 32.8, 27.3, 27.0, 26.9, 26.7, 25.9, 25.5, 25.4, 24.6, 19.2, 19.1; HRMS (FAB, ${\left.\mathrm{M}+\mathrm{Na}^{+}\right)}^{+}$ calcd for $\mathrm{C}_{57} \mathrm{H}_{71} \mathrm{NaO}_{6} \mathrm{Si}_{2}$ 965.4375, found 965.4383.

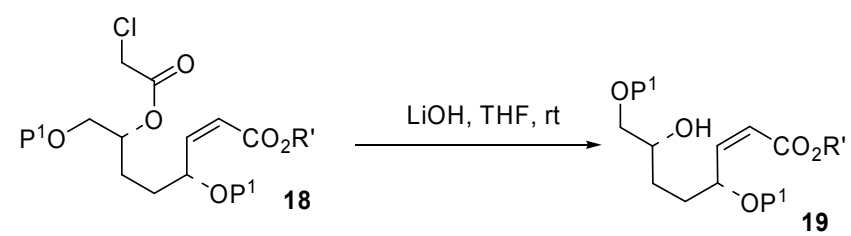


butyl(diphenyl)silyl]oxy\}-7-hydroxyoct-2-enoate (19). To a stirred solution of chloroacetace 82 $(1.30 \mathrm{~g}, 0.837 \mathrm{mmol})$ in THF $(50 \mathrm{~mL})$ was added $\mathrm{LiOH}\left(30 \mathrm{~mL}, 0.4 \mathrm{M}\right.$ aq) dropwise at $0{ }^{\circ} \mathrm{C}$. The reaction was then stirred for $2.5 \mathrm{~h}$, poured into phosphate buffer $(\mathrm{pH}$ 7) and partitioned between EtOAc and phosphate buffer ( $\mathrm{pH} 7)$. The combined organic phases were dried $\left(\mathrm{MgSO}_{4}\right)$, filtered and concentrated in vacuo to afford a crude oil. Purification by flash chromatography (3.1312.5\% EtOAc/heptane) furnished a separable mixture of secondary and primary alcohols, 19:19a (92:8), as a clear oil $(1.10 \mathrm{~g}, 92 \%):[\alpha]_{\mathrm{D}}^{23}-31.5\left(\mathrm{c}=1.0, \mathrm{CH}_{2} \mathrm{Cl}_{2}\right)$; IR (film) $3567(\mathrm{br}, \mathrm{s}), 3070$ (w), 2931 (s), 2858 (s), 1712 (s), 1427 (s), 1193 (s), 1112 (s), 701 (s); ${ }^{1} \mathrm{H}$ NMR (500 MHz, $\left.\mathrm{CDCl}_{3}\right) \delta$ 7.77-7.71 (m, 4H), 7.67-7.58 (m, 4H), 7.54-7.35 (m, 8H), 7.26-7.20 (m, 8H), 7.18-7.11 (m, 1H), 6.04 (dd, $J=11.7,7.8 \mathrm{~Hz}, 1 \mathrm{H}), 5.46-5.46-5.39$ (m, 1H), 4.81 (dd, $J=11.7,1.0 \mathrm{~Hz}, 1 \mathrm{H})$, $4.66(\mathrm{dt}, J=10.3,4.2,1 \mathrm{H}), 3.78-3.70(\mathrm{~m}, 1 \mathrm{H}), 3.64(\mathrm{dd}, J=10.1,3.6 \mathrm{~Hz}, 1 \mathrm{H}), 3.52(\mathrm{dd}, J=10.0$, $7.3 \mathrm{~Hz}, 1 \mathrm{H}), 2.69$ (br s, 1H), $2.02(\mathrm{dt}, J=11.3,2.2 \mathrm{~Hz}, 1 \mathrm{H}), 1.93-0.87(\mathrm{~m}, 12 \mathrm{H}), 1.25(\mathrm{~s}, 3 \mathrm{H})$, 1.21 (s 3H), 1.13 (s, 9H), 1.08 (s, 9H); ${ }^{13} \mathrm{C}$ NMR (125 MHz, $\left.\mathrm{CDCl}_{3}\right) \delta$ 165.0, 152.7, 151.8, $136.27,136.22,136.0,134.6,134.3,133.7,130.2,130.0,129.9,128.3,128.2,127.9,127.8$, $125.8,125.4,118.5,74.6,72.0,70.0,68.5,51.3,40.2,33.7,28.4,27.8,27.4,27.3,26.3,25.8$, 25.1, 19.76, 19.73; HRMS (FAB, $\mathrm{M}+\mathrm{Na}^{+}$) calcd for $\mathrm{C}_{55} \mathrm{H}_{70} \mathrm{NaO}_{5} \mathrm{Si}_{2} 889.4659$, found 889.4643.
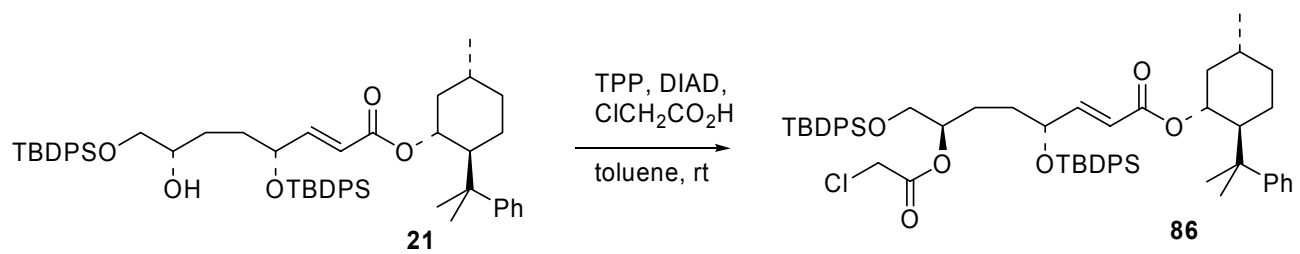

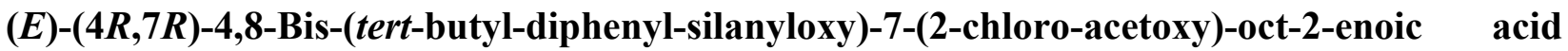

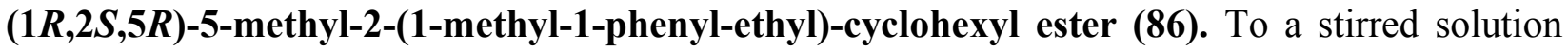
of secondary alcohol 21 (130 mg, $0.15 \mathrm{mmol})$, triphenylphosphine (77 $\mathrm{mg}, 0.30 \mathrm{mmol})$ and 
chloroacetic acid $(28 \mathrm{mg}, 0.30 \mathrm{mmol})$ in toluene $(10 \mathrm{~mL})$ was added DIAD $(58 \mu \mathrm{L}, 0.28 \mathrm{mmol})$ dropwise over 10 min at rt. The yellowish mixture turned clear over 5 min and was stirred for 2.5 h. The reaction was then quenched by evaporation onto silica. Purification by flash chromatography (1.56-6.25\% EtOAc/heptane) afforded ester 86 as a clear oil (134 mg, 95\%): $[\alpha]_{\mathrm{D}}^{23}+11.7\left(c=1.0, \mathrm{CH}_{2} \mathrm{Cl}_{2}\right)$; IR (film) $3070(\mathrm{w}), 2856(\mathrm{~m}), 2858(\mathrm{~m}), 1762(\mathrm{~m}), 1721(\mathrm{~s}), 1427$ (m), $1276(\mathrm{~m}), 1170$ (m), 1112 (s); ${ }^{1} \mathrm{H}$ NMR (400 MHz, $\left.\mathrm{CDCl}_{3}\right) \delta$ 7.73-7.59 (m, 8H), 7.54-7.34 (m, 12H), 7.33-7.24 (m, 4H), 7.16-7.10 (m, 1H), 6.69 (dd, $J=15.6,5.2 \mathrm{~Hz}, 1 \mathrm{H}$ major), 6.32 (dd, $J=15.6,5.1 \mathrm{~Hz}, 1 \mathrm{H}$ minor), $5.69(\mathrm{dd}, J=15.6,1.4 \mathrm{~Hz}, 1 \mathrm{H}), 5.00-4.91(\mathrm{~m}, 1 \mathrm{H}), 4.90(\mathrm{dt}, J=$ 10.7, $4.3 \mathrm{~Hz}, 1 \mathrm{H}), 4.38$ (q, $J=4.4 \mathrm{~Hz}, 1 \mathrm{H}), 3.94(\mathrm{~m}, 2 \mathrm{H}), 3.68-3.59(\mathrm{~m}, 2 \mathrm{H}), 2.05-1.91(\mathrm{~m}, 2 \mathrm{H})$, 1.75-0.78 (m, 10H), $1.35(\mathrm{~s}, 3 \mathrm{H}), 1.30(\mathrm{~s}, 3 \mathrm{H}), 1.11(\mathrm{~s}, 9 \mathrm{H}), 1.09$ (s, 9H), 0.93 (d, $J=6.5 \mathrm{~Hz}, 3 \mathrm{H})$; ${ }^{13} \mathrm{C}$ NMR $\left(100 \mathrm{MHz}, \mathrm{CDCl}_{3}\right) \delta 167.2,165.9,151.3,149.2,136.2,136.1,136.0,135.9,134.1$, $133.6,133.5,130.3,130.2,128.3,128.2,128.1,128.0,125.9,125.6,121.9,76.8,75.1,72.1,65.2$, $51.0,42.2,41.3,40.5,35.0,32.5,32.3,31.7,29.4,28.5,27.4,27.2,25.8,25.3,23.1,22.2,19.7$, 19.6, 14.5; HRMS (FAB, Na ${ }^{+}$) calcd for $\mathrm{C}_{58} \mathrm{H}_{73} \mathrm{ClNaO}_{6} \mathrm{Si}_{2}$ 979.4532, found 979.4550 .

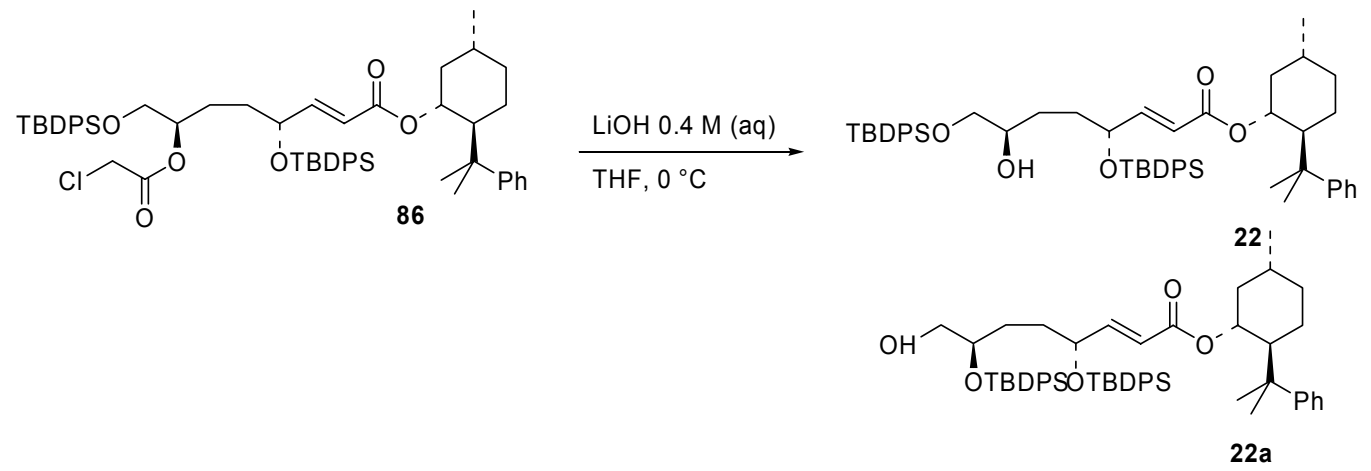

$(E)-(4 R, 7 R)-4,8$-Bis-(tert-butyl-diphenyl-silanyloxy)-7-hydroxy-oct-2-enoic acid $(1 R, 2 S, 5 R)$ 5-methyl-2-(1-methyl-1-phenyl-ethyl)-cyclohexyl ester (22). To a stirred solution of chloroacetace $86(550 \mathrm{mg}, 0.575 \mathrm{mmol})$ in THF $(50 \mathrm{~mL})$ was added $\mathrm{LiOH}(12.5 \mathrm{~mL}, 0.4 \mathrm{M} \mathrm{aq})$ 
dropwise at $0{ }^{\circ} \mathrm{C}$. The reaction was then stirred for 50 min, poured into phosphate buffer $(\mathrm{pH} 7)$ and partitioned between EtOAc and phosphate buffer $(\mathrm{pH} 7)$. The combined organic phases were dried $\left(\mathrm{MgSO}_{4}\right)$, filtered and concentrated in vacuo to afford a crude oil. Purification by flash chromatography (3.13-12.5\% EtOAc/heptane) furnished an inseparable mixture of secondary and primary alcohols, 22/22a (91:9), as a clear oil (506 mg, 99\%): $[\alpha]_{\mathrm{D}}{ }^{23}+13.8\left(c=1.0, \mathrm{CH}_{2} \mathrm{Cl}_{2}\right)$; IR (film) 2929 (m), 2857 (m), 1711 (m), 1471 (w)m 1272 (w), 1112 (s), 822 (w); ${ }^{1}$ H NMR (400 $\left.\mathrm{MHz}, \mathrm{CDCl}_{3}\right) \delta$ 7.66-7.53 (m, 8H), 7.47-7.19 (m, 16H), 7.11-7.04 (m, 1H) $6.66(\mathrm{dd}, J=15.6,5.1$ Hz, 1H major), 6.58 (dd, $J=15.6,5.2 \mathrm{~Hz}, 1 \mathrm{H}$ minor diastereomer), 6.25 (dd, $J=15.6,5.0 \mathrm{~Hz}, 1 \mathrm{H}$ primary alcohol), $5.61(\mathrm{dd}, J=15.6,1.5 \mathrm{~Hz}, 1 \mathrm{H}), 4.83(\mathrm{dt}, J=10.6,4.3 \mathrm{~Hz}, 1 \mathrm{H}), 4.34$ (q, $J=$ 4.5Hz, 1H), 3.59-3.24 (m, 4H), $2.36(\mathrm{~s}$ br, $1 \mathrm{H}), 1.98-1.85(\mathrm{~m}, 3 \mathrm{H}), 1.68-0.67(\mathrm{~m}, 8 \mathrm{H}), 1.28(\mathrm{~s}$, 3H), $1.23(\mathrm{~s}, 3 \mathrm{H}), 1.05(\mathrm{~s}, 9 \mathrm{H}), 1.04(\mathrm{~s}, 9 \mathrm{H}), 0.86(\mathrm{~d}, J=6.5 \mathrm{~Hz}, 3 \mathrm{H}) ;{ }^{13} \mathrm{C}$ NMR (400 MHz, $\left.\mathrm{CDCl}_{3}\right) \delta 166.1,151.3,149.8,136.29,136.26,136.06,136.01,134.3,133.8,133.6,133.5,130.36$, $130.35,130.32,130.2,128.4,128.3,128.2,128.1,128.0,126.0,125.7,121.6,75.0,72.5,72.3$, $68.4,51.1,42.3,40.5,35.0,33.0,31.8,28.5,27.56,27.54,27.4,27.3,25.9,22.3,19.8,19.7$; HRMS (FAB, $\mathrm{Na}^{+}$) calcd for $\mathrm{C}_{56} \mathrm{H}_{72} \mathrm{NaO}_{5} \mathrm{Si}_{2}$ 903.4816, found 903.4839 .

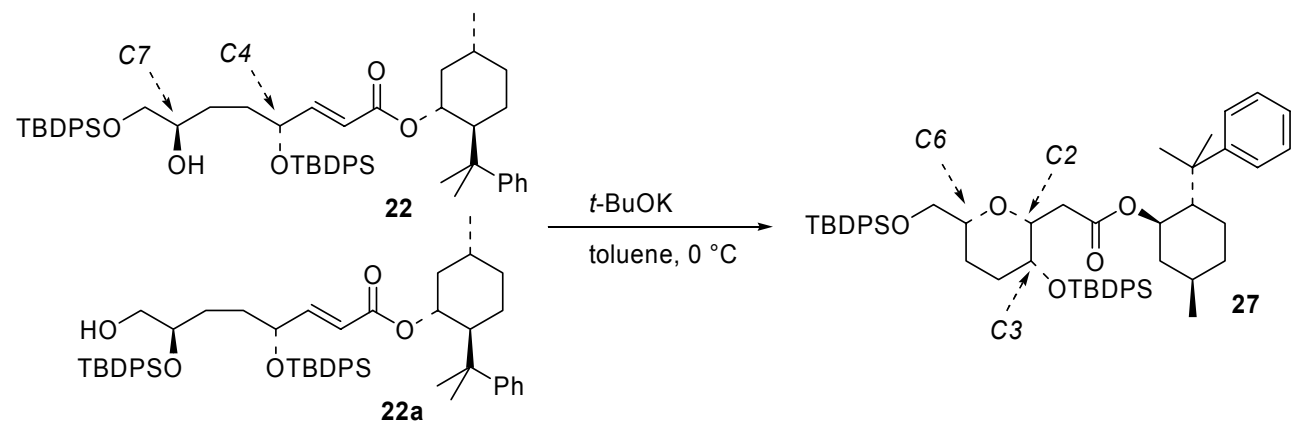

[(2R,3R,6R)-3-(tert-Butyl-diphenyl-silanyloxy)-6-(tert-butyl-diphenyl-silanyloxymethyl)tetrahydro-pyran-2-yl]-acetic acid $\quad(1 R, 2 S, 5 R)-5$-methyl-2-(1-methyl-1-phenyl-ethyl)cyclohexyl ester (27). To a mixture of 22 and 22a (91:9) (24.7 mg, $0.028 \mathrm{mmol})$ in toluene (2.8 
$\mathrm{mL})$ at $0{ }^{\circ} \mathrm{C}$ was added t-BuOK $(3.14 \mathrm{mg}, 0.028 \mathrm{mmol}$, in $0.314 \mathrm{~mL}$ toluene $)$. The reaction was stirred for $1 \mathrm{~h}$, then quenched by addition of phosphate buffer $(\mathrm{pH} 7)$ and partitioned between EtOAc and phosphate buffer $(\mathrm{pH} 7)$. The combined organic phases were dried $\left(\mathrm{MgSO}_{4}\right)$, filtered and concentrated in vacuo to afford the cyclized product 27 as clear a oil, pure by NMR (24.8 mg, quant.): Diastereomeric ratio, $(2 R):(2 S)$ epimers $\geq 95: 5^{4} ;[\alpha]_{\mathrm{D}}^{23}+3.8\left(c=1.0, \mathrm{CH}_{2} \mathrm{Cl}_{2}\right)$; IR (film) 3071 (m), 2929 (s), 2857 (m), 1728 (s), 1427 (m), 1278 (m), 1175 (m), 1112 (s), 822 (m), 701 (s); ${ }^{1} \mathrm{H}$ NMR $(500 \mathrm{MHz}) \delta$ 7.78-7.68 (m, 8H), 7.52-7.17 (m, 16H), 7.12-7.06 (m, 1H), $4.75(\mathrm{dt}, J=$ 10.6, 4.4 Hz, 1H), $3.70(\mathrm{dd}, J=10.2,4.9 \mathrm{~Hz}, 1 \mathrm{H}), 3.64(\mathrm{~s}, 1 \mathrm{H}), 3.56$ (dd, $J=10.2,5.8 \mathrm{~Hz}, 1 \mathrm{H})$, 3.50 (ddd, $J=8.7,3.9,0.8 \mathrm{~Hz}, 1 \mathrm{H}), 3.43(\mathrm{td}, J=10.4,5.1 \mathrm{~Hz}, 1 \mathrm{H}), 3.17(\mathrm{dd}, J=7.7,3.7 \mathrm{~Hz}$, minor (2S,3S,6S)-27), $2.33(\mathrm{dd}, J=15.8,8.8 \mathrm{~Hz}, 1 \mathrm{H}), 1.95-1-86(\mathrm{~m}, 1 \mathrm{H}), 1.85-1.85(\mathrm{~m}, 2 \mathrm{H})$, 1.78-1.71 (m, 3H), 1.62-0.65 (m, 7H), $1.24(\mathrm{~s}, 3 \mathrm{H}), 1.16(\mathrm{~s}, 3 \mathrm{H}), 1.04(\mathrm{~s}, 9 \mathrm{H}), 1.03(\mathrm{~s}, 9 \mathrm{H}), 0.72$ $(\mathrm{d}, J=6.5 \mathrm{~Hz}, 3 \mathrm{H})$. Spectrum contains traces of acetone; ${ }^{13} \mathrm{C} \mathrm{NMR}\left(125 \mathrm{MHz}, \mathrm{CDCl}_{3}\right) \delta 171.1$, $151.1,135.9,135.7,135.6,134.4,133.8,129.6,129.5,129.4,127.8,127.6,127.4,125.5,77.8$, $74.5,68.2,67.1,50.3,41.6,39.9,38.5,34.5,31.2,30.4,27.2,26.9,26.8,26.3,22.1,21.7,19.6$, 19.3. Spectrum contains traces of acetone; HRMS (FAB, $\mathrm{Na}^{+}$) calcd for $\mathrm{C}_{56} \mathrm{H}_{72} \mathrm{NaO}_{5} \mathrm{Si}_{2}$ 903.4816, found 903.4843.

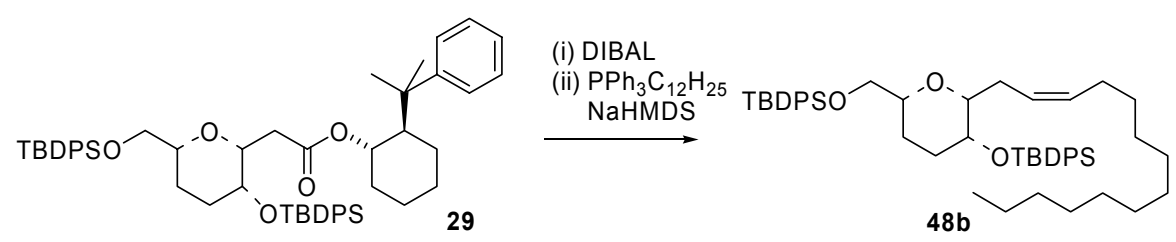

$(2 R, 3 R, 6 R)-3-\{[$ tert-Butyl(diphenyl)silyl]oxy\}-6-\{[tert-butyl(diphenyl)silyl]oxymethyl\}-2-[(Z)tetradec-2-enyl]-tetrahydro-2H-pyran (48b). To a stirred solution of ester $29(210 \mathrm{mg}, 0.24$ mmol $)$ in $\mathrm{CH}_{2} \mathrm{Cl}_{2}(5 \mathrm{~mL})$ at $-78{ }^{\circ} \mathrm{C}$ was added DIBAL-H $(240 \mu \mathrm{L}, 0.36 \mathrm{mmol}, 1.5 \mathrm{M}$ in toluene $)$ dropwise over $5 \mathrm{~min}$. The resulting mixture was stirred for $15 \mathrm{~min}$, after which a preformed (30 
min) solution of dodecyl triphenylphosphonium bromide (372 $\mathrm{mg}, 0.73 \mathrm{mmol})$ and NaHMDS (1.16 mL, $0.696 \mathrm{mmol}, 0.6 \mathrm{M}$ in toluene) in THF $(15 \mathrm{~mL})$ at $0{ }^{\circ} \mathrm{C}$ was added via a cannula. The temperature was raised to $0{ }^{\circ} \mathrm{C}$ over $12 \mathrm{~h}$ and the reaction was then quenched by evaporation onto silica. Purification by flash chromatography (0.78-3.13\% EtOAc/heptane) furnished olefin $\mathbf{4 8 b}$ as a clear oil (157 mg, 78\%): $[\alpha]_{\mathrm{D}}^{23}+13.2\left(c=1.0, \mathrm{CH}_{2} \mathrm{Cl}_{2}\right)$; IR (film) $3070(\mathrm{w}), 2927(\mathrm{~s}), 2856(\mathrm{~s})$, 1471 (m), 1427 (m), 1112 (s), 701 (s); ${ }^{1} \mathrm{H}$ NMR (500 MHz, $\left.\mathrm{CDCl}_{3}\right) \delta$ 7.81-7.65 (m, 8H), 7.49$7.30(\mathrm{~m}, 12 \mathrm{H}), 3.85$ (dd, $J=10.3,5.4 \mathrm{~Hz}, 1 \mathrm{H}), 3.73(\mathrm{~s}, 1 \mathrm{H}), 3.69$ (dd, $J=10.3,5.4 \mathrm{~Hz}, 1 \mathrm{H}), 3.46-$ $3.54(\mathrm{~m}, 1 \mathrm{H}), 3.19(\mathrm{dd}, J=8.2,5.2 \mathrm{~Hz}, 1 \mathrm{H}), 2.48-2.30(\mathrm{~m}, 1 \mathrm{H}), 2.11-1.99(\mathrm{~m}, 1 \mathrm{H}), 1.97-1.73(\mathrm{~m}$, $4 \mathrm{H}), \quad 1.51-1.38(\mathrm{~m}, 3 \mathrm{H}), 1.38-0.96(\mathrm{~m}, 37 \mathrm{H}), 0.92(\mathrm{t}, J=6.9 \mathrm{~Hz}, 3 \mathrm{H}) ;{ }^{13} \mathrm{C} \mathrm{NMR}(125 \mathrm{MHz}$, $\left.\mathrm{CDCl}_{3}\right) \delta 136.0,135.7,134.5,134.0,133.9,133.8,133.7,133.6,132.6,131.1,129.5,129.4$ $128.6,128.49,128.43,128.35,128.30,127.5,127.47,127.40,126.2,80.5,78.1,68.0,67.4,31.9$, 30.7, 30.5, 29.6, 29.5, 29.36, 29.33, 27.4, 27.1, 26.8, 22.6, 22.5, 19.6, 19.3, 14.1; HRMS (FAB, $\mathrm{M}+\mathrm{Na}^{+}$) calcd for $\mathrm{C}_{52} \mathrm{H}_{74} \mathrm{NaO}_{3} \mathrm{Si}_{2}$ 825.5074, found 825.5057.

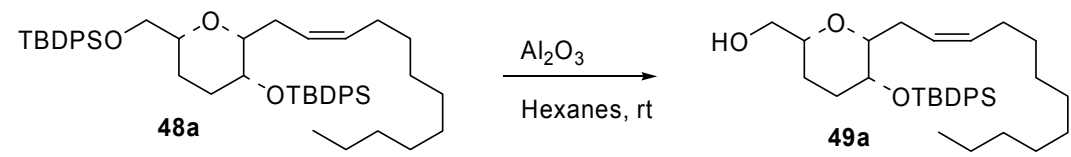

$\{(2 R, 3 R, 6 R)-5-\{[$ tert-Butyl(diphenyl)silyl] $] 0 x y\}-6-[(Z)$-dodec-2-enyl]-tetrahydro-2H-pyran-2-

yl\}-methanol (49a). To a solution of bis-silyl ether 48a (270 mg, $0.336 \mathrm{mmol})$ in hexanes (20 $\mathrm{mL}, \mathrm{HPLC}$ grade) was added activated $\mathrm{Al}_{2} \mathrm{O}_{3}\left(11.34 \mathrm{~g}\right.$, dried $18 \mathrm{~h}$ at $\left.120{ }^{\circ} \mathrm{C}, 0.01 \mathrm{mmHg}\right)$. The mixture was stirred for $24 \mathrm{~h}$ and $\mathrm{MeOH}(20 \mathrm{~mL})$ was added. After stirring an additional $15 \mathrm{~min}$ the mixture was filtered and concentrated in vacuo to afford a crude oil. Purification by flash chromatography (12.5-25\% EtOAc/heptane) afforded the primary alcohol 49a as a clear oil (157 mg, 83\%): $[\alpha]_{\mathrm{D}}^{23}+28.2\left(\mathrm{c}=1.0, \mathrm{CH}_{2} \mathrm{Cl}_{2}\right.$ ); IR (film) $3421(\mathrm{br}, \mathrm{m}), 2925(\mathrm{~s}), 2854(\mathrm{~s}), 1457(\mathrm{w})$, 
1427 (w), 1110 (s), 1031 (s); ${ }^{1} \mathrm{H}$ NMR (500 MHz, $\left.\mathrm{CDCl}_{3}\right) \delta$ 7.78-7.62 (m, 4H), 7.48-7.31 (m, $6 \mathrm{H}), 5.46-5.15(\mathrm{~m}, 2 \mathrm{H}), 3.76-3.73(\mathrm{~m}, 1 \mathrm{H}), 3.54-3.64(\mathrm{~m}, 2 \mathrm{H}), 3.52-3.44(\mathrm{~m}, 1 \mathrm{H}), 3.21(\mathrm{dd}, J=$ 8.6, 4.9 Hz, 1H), $2.46(\mathrm{td}, J=15.8,8.0 \mathrm{~Hz}, 1 \mathrm{H}), 2.69$ (br s, 1H), 2.04-1.66 (m, 5H), 1.52-1.40 (m, $1 \mathrm{H}), 1.38-1.059(\mathrm{~m}, 15 \mathrm{H}), 1.13(\mathrm{~s}, 9 \mathrm{H}), 0.90(\mathrm{t}, J=6.9 \mathrm{~Hz}, 3 \mathrm{H}) ;{ }^{13} \mathrm{C} \mathrm{NMR}\left(125 \mathrm{MHz}, \mathrm{CDCl}_{3}\right) \delta$ $136.00,135.97,134.4,133.9,131.6,129.5,127.5,127.4,125.7,80.3,77.7,67.9,66.2,31.9,30.5$, $30.4,29.6,29.55,29.53,29.33,29.31,27.4,27.1,22.6,21.5,19.6,14.1 ; \mathrm{HRMS}\left(\mathrm{FAB}, \mathrm{M}+\mathrm{Na}^{+}\right)$ calcd for $\mathrm{C}_{34} \mathrm{H}_{53} \mathrm{O}_{3} \mathrm{Si} 537.3764$, found 537.3754.

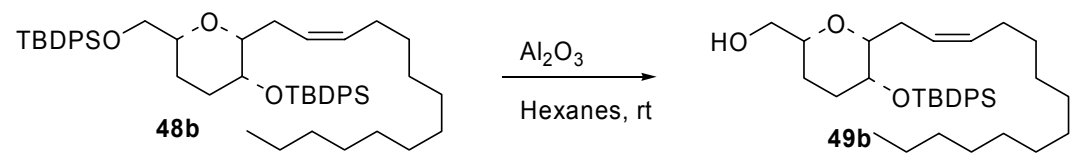

$\{(2 R, 3 R, 6 R)-5-\{[$ tert-Butyl(diphenyl)silyl]oxy $\}-6-[(Z)$-tetradec-2-enyl]-tetrahydro-2H-pyran-

2-yl\}-methanol (49b). To a solution of bis-silyl ether $\mathbf{4 8 b}(290 \mathrm{mg}, 0.348 \mathrm{mmol})$ in hexanes (20 mL, HPLC grade) was added activated $\mathrm{Al}_{2} \mathrm{O}_{3}\left(11.3 \mathrm{~g}\right.$, dried $18 \mathrm{~h}$ at $\left.120{ }^{\circ} \mathrm{C}, 0.01 \mathrm{mmHg}\right)$. The mixture was stirred for $24 \mathrm{~h}$ and $\mathrm{MeOH}(20 \mathrm{~mL})$ was added. After stirring an additional $15 \mathrm{~min}$ the mixture was filtered and concentrated in vacuo to afford a crude oil. Purification by flash chromatography (12.5-25\% EtOAc/heptane) afforded the primary alcohol 49b as a clear oil (160 mg, 81\%): $[\alpha]_{\mathrm{D}}^{23}+21.5\left(c=1.0, \mathrm{CH}_{2} \mathrm{Cl}_{2}\right)$; IR (film) 3467 (br, m), 2925 (s), $2854(\mathrm{~s}), 1470(\mathrm{~m})$, 1110 (s), 1031 (m), 703 (s); ${ }^{1} \mathrm{H}$ NMR (500 MHz, $\left.\mathrm{CDCl}_{3}\right) \delta$ 7.45-7.61 (m, 4H), 7.61-7.31 (m, 6H), $5.42(\mathrm{~m}, 2 \mathrm{H}), 3.77-3.65(\mathrm{~m}, 1 \mathrm{H}), 3.64-3.53(\mathrm{~m}, 2 \mathrm{H}), 3.53-3.39(\mathrm{~m}, 1 \mathrm{H}), 3.20(\mathrm{dd}, J=8.6,5.0 \mathrm{~Hz}$ 1H), $2.44(\mathrm{td}, J=15.4,7.7 \mathrm{~Hz}, 1 \mathrm{H}), 2.37-0.92(\mathrm{~m}, 35 \mathrm{H}), 0.88(\mathrm{t}, J=6.9 \mathrm{~Hz}, 3 \mathrm{H}) ;{ }^{13} \mathrm{C} \mathrm{NMR}(125$ $\left.\mathrm{MHz}_{,} \mathrm{CDCl}_{3}\right) \delta 136.05,136.02,135.9,135.8,135.7,134.4,133.9,132.7,131.7,129.6,127.5$, $127.47,127.43,125.8,97.5,80.6,80.3,77.7,68.0,66.2,31.9,30.56,30.51,29.7,29.6,29.58$, 29.56, 29.37, 29.33, 27.4, 27.1, 21.5, 19.6, 14.1; HRMS (FAB, M+ $\mathrm{H}^{+}$) calcd for $\mathrm{C}_{36} \mathrm{H}_{57} \mathrm{O}_{3} \mathrm{Si}$ 565.4077, found 565.4066. 


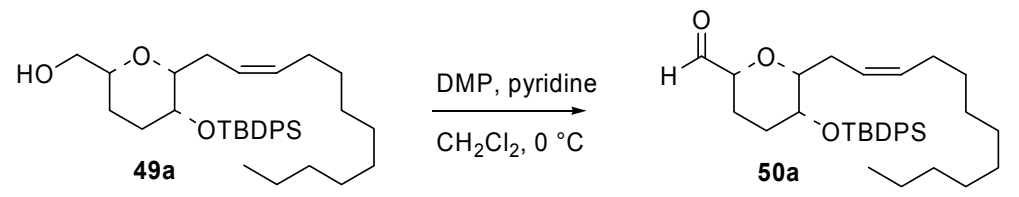

$(2 R, 3 R, 6 R)-5-\{[$ tert-Butyl(diphenyl)silyl $]$ oxy $\}-6-[(Z)-\quad$ dec-2-enyl]-tetrahydro-2H-pyran-2carbaldehyde (50a). To a solution of primary alcohol 49a (147 $\mathrm{mg}, 0.259 \mathrm{mmol})$ and pyridine (64 $\mu \mathrm{L}, 0.778 \mathrm{mmol})$ in $\mathrm{CH}_{2} \mathrm{Cl}_{2}(3.0 \mathrm{~mL})$ was added, in one portion, Dess-Martin periodinane (165 mg, $0.390 \mathrm{mmol})$ at $0{ }^{\circ} \mathrm{C}$. The reaction mixture was stirred $3 \mathrm{~h}$, after which $\mathrm{Na}_{2} \mathrm{~S}_{2} \mathrm{O}_{3}(5 \mathrm{~mL}$, $20 \%$ aq) was added and the reaction was stirred for an additional 10 min. The reaction mixture was then partitioned between EtOAc and $\mathrm{Na}_{2} \mathrm{~S}_{2} \mathrm{O}_{3}(20 \%$, aq). The combined organic phases were dried $\left(\mathrm{MgSO}_{4}\right)$, filtered and concentrated in vacuo. Purification by flash chromatography (6.25$12.5 \% \mathrm{EtOAc} / \mathrm{heptane})$ afforded aldehyde $\mathbf{5 0 a}$ as a clear oil $(125 \mathrm{mg}, 81 \%):[\alpha]_{\mathrm{D}}^{23}+55.0(\mathrm{c}=1.0$, CH $\mathrm{CH}_{2}$ ); IR (film) 2927 (s), 2856 (s), 1739 (s), 1427 (m), 1110 (s), 701 (s); ${ }^{1} \mathrm{H}$ NMR (MHz, $\left.\mathrm{CDCl}_{3}\right) \delta 9.72(\mathrm{~s}, 1 \mathrm{H}), 7.77-6.60(\mathrm{~m}, 4 \mathrm{H}), 7.49-7.32(\mathrm{~m}, 6 \mathrm{H})$, 5.46-5.17 (m, 2H), 3.82-3.72 (m, 2H), $3.25(\mathrm{dd}, J=8.3,4.5 \mathrm{~Hz}, 1 \mathrm{H}), 2.56-2.46(\mathrm{~m}, 1 \mathrm{H}), 2.11-1.78(\mathrm{~m}, 5 \mathrm{H}), 1.61-1.40(\mathrm{~m}, 3 \mathrm{H})$, $1.37-1.00(\mathrm{~m}, 13 \mathrm{H}), 1.10(\mathrm{~s}, 9 \mathrm{H}), 0.89(\mathrm{t}, J=6.9 \mathrm{~Hz}, 3 \mathrm{H}) ;{ }^{13} \mathrm{C} \mathrm{NMR}\left(125 \mathrm{MHz}, \mathrm{CDCl}_{3}\right) \delta 202.6$, $136.0,135.9,135.2,134.1,133.6,131.9,129.7,127.6,127.58,127.55,125.4,81.6,80.7,67.5$, $31.9,30.4,30.3,29.6,29.57,29.54,29.3,27.4,27.1,22.6,20.5,19.6,14.1$; HRMS (ES+, $\mathrm{M}+\mathrm{Na}^{+}$) calcd for $\mathrm{C}_{34} \mathrm{H}_{50} \mathrm{NaO}_{3} \mathrm{Si} 557.3427$, found 557.3442.
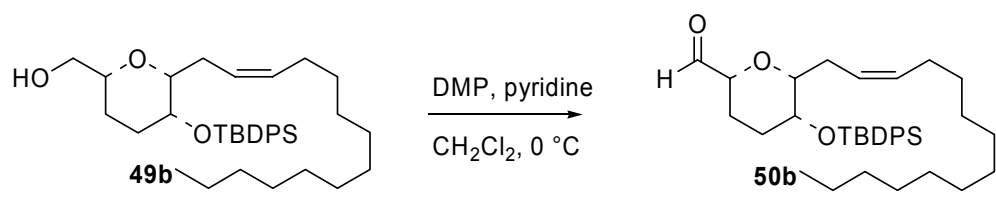

$(2 R, 3 R, 6 R)-5-\{[$ tert-Butyl(diphenyl)silyl]oxy\}-6-[(Z)-tetradec-2-enyl]-tetrahydro-2H-pyran-

2-carbaldehyde (50b). To a solution of primary alcohol 49b (33 mg, $0.060 \mathrm{mmol})$ in $\mathrm{CH}_{2} \mathrm{Cl}_{2}$ $(1.5 \mathrm{~mL})$ was added, in one portion, Dess-Martin periodinane $(33 \mathrm{mg}, 0.078 \mathrm{mmol})$ at $0{ }^{\circ} \mathrm{C}$. The reaction mixture was stirred $4 \mathrm{~h}$, after which $\mathrm{Na}_{2} \mathrm{~S}_{2} \mathrm{O}_{3}(5 \mathrm{~mL}, 20 \%$ aq) was added and the reaction 
was stirred for an additional $10 \mathrm{~min}$. The reaction mixture was then partitioned between EtOAc and $\mathrm{Na}_{2} \mathrm{~S}_{2} \mathrm{O}_{3}\left(20 \%\right.$, aq). The combined organic phases were dried $\left(\mathrm{MgSO}_{4}\right)$, filtered and concentrated in vacuo. Purification by flash chromatography (6.25-12.5\% EtOAc/heptane) afforded aldehyde $\mathbf{5 0 b}$ as a clear oil $(28 \mathrm{mg}, 83 \%):[\alpha]_{\mathrm{D}}^{23}+31.2\left(c=0.91, \mathrm{CH}_{2} \mathrm{Cl}_{2}\right)$; IR (film) 2925 (s), 2854 (s), 1739 (m), 1427 (m), 1106 (s); ${ }^{1} \mathrm{H}$ NMR (400 MHz, CDCl $) \delta 9.71$ (s, 1H), 7.77-7.64 (m, 4H), 7.48-7.40 (m, 6H), 5.47-5.14 (m, 2H), $3.78(\mathrm{dd}, J=11.9,2.3 \mathrm{~Hz}, 1 \mathrm{H}), 3.74(\mathrm{~s}$, 1H), $3.24(\mathrm{dd}, J=8.6,4.7 \mathrm{~Hz}, 1 \mathrm{H}), 2.51(\mathrm{td}, J=15.4,7.6 \mathrm{~Hz}, 1 \mathrm{H}), 2.09-1.70(\mathrm{~m}, 4 \mathrm{H}), 1.62-0.96$ $(\mathrm{m}, 30 \mathrm{H}), 0.88(\mathrm{t}, J=6.8 \mathrm{~Hz}, 3 \mathrm{H}) ;{ }^{13} \mathrm{C} \mathrm{NMR}\left(100 \mathrm{MHz}, \mathrm{CDCl}_{3}\right) \delta 202.6,136.0,135.9,134.1$, $133.7,131.9,129.7,129.6,127.57,127.55,125.4,81.6,80.7,67.5,31.9,30.4,30.3,29.6,29.58$, 29.54, 29.36, 29.34, 27.4, 27.1, 22.6, 20.5, 19.6, 14.1; HRMS (FAB, M+H ${ }^{+}$) calcd for $\mathrm{C}_{36} \mathrm{H}_{55} \mathrm{O}_{3} \mathrm{Si}$ 563.3920, found 563.3919.

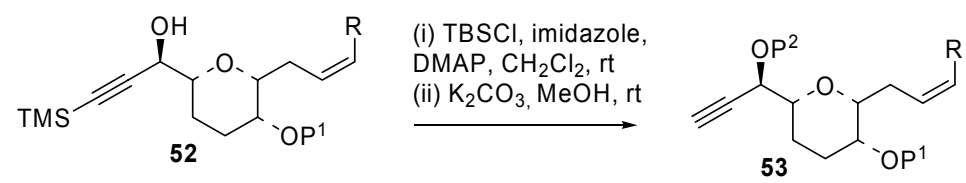

$(2 R, 3 R, 6 R)-3-\{[$ tert-Butyl(diphenyl)silyl]oxy\}-6-\{(R)-1-\{[tert-butyl(dimethyl)silyl]oxy $\}-p r o p-$ 2-ynyl\}-2-[(Z)-dodec-2-enyl]-tetrahydro-2H-pyran (53). To a stirred solution of propargylic alcohol 52 (105 $\mathrm{mg}, 0.166 \mathrm{mmol})$ in $\mathrm{CH}_{2} \mathrm{Cl}_{2}(2.5 \mathrm{~mL})$ at $\mathrm{rt}$, was added $t$-butyldimetylsilyl chloride (49 $\mathrm{mg}, 0.332 \mathrm{mmol})$ and imidazole $(56.5 \mathrm{mg}, 0.829 \mathrm{mmol})$ in one portion respectively at $\mathrm{rt}$. The resulting suspension was stirred for $2 \mathrm{~h}$, and then $\mathrm{MeOH}(2.5 \mathrm{~mL})$ followed by $\mathrm{K}_{2} \mathrm{CO}_{3}$ (120 mg, $0.868 \mathrm{mmol}$ ) was added. The resulting mixture was stirred a further $14 \mathrm{~h}$, after which the reaction was quenched by addition of phosphate buffer $(\mathrm{pH} 7)$ and partitioned between EtOAc and phosphate buffer $(\mathrm{pH} 7)$. The combined organic phases were dried $\left(\mathrm{MgSO}_{4}\right)$, filtered and concentrated in vacuo. Purification by flash chromatography (1.56\% EtOAc/heptane) furnished alkyne 53 as a clear oil $(105 \mathrm{mg}, 93 \%)$ : $[\alpha]_{\mathrm{D}}{ }^{23}+29.1\left(\mathrm{c}=1.0, \mathrm{CH}_{2} \mathrm{Cl}_{2}\right)$; IR (film) $3070(\mathrm{w}), 2927$ 
(s), 2856 (s), 1608 (w), $1471(\mathrm{~m}), 1253(\mathrm{~m}), 1110(\mathrm{~s}), 836(\mathrm{~m}), 701$ (s); ${ }^{1} \mathrm{H}$ NMR (MHz, $\left.\mathrm{CDCl}_{3}\right) \delta$ 7.79-7.64 (m, 4H), 7.48-7.31 (m, 6H), 5.37-5.12 (m, 2H), $4.43(\mathrm{dd}, J=6.4,2.1 \mathrm{~Hz}, 1 \mathrm{H}), 3.75-$ $3.71(\mathrm{~m}, 1 \mathrm{H}), 3.39$ (ddd, $J=11.4,6.4,2.2 \mathrm{~Hz}, 1 \mathrm{H}), 3.14(\mathrm{dd}, J=8.1,5.4 \mathrm{~Hz}, 1 \mathrm{H}), 2.41$ (d, $J=2.1$ $\mathrm{Hz}, 1 \mathrm{H}), 2.40-2.30(\mathrm{~m}, 1 \mathrm{H}), 2.01-1.75(\mathrm{~m}, 5 \mathrm{H}), 1.62-1.55(\mathrm{~m}, 1 \mathrm{H}), 1.51-1.41(\mathrm{~m}, 1 \mathrm{H}), 1.38-0.92$ (m, 14H), $1.11(\mathrm{~s}, 9 \mathrm{H}), 0.94(\mathrm{~s}, 9 \mathrm{H}), 0.90(\mathrm{t}, J=7.0 \mathrm{~Hz}, 3 \mathrm{H}), 0.19(\mathrm{~s}, 3 \mathrm{H}), 0.15(\mathrm{~s}, 3 \mathrm{H}) ;{ }^{13} \mathrm{C} \mathrm{NMR}$ $\left(125 \mathrm{MHz}, \mathrm{CDCl}_{3}\right) \delta 136.5,136.4,134.5,131.5,130.0,129.9,127.8,126.6,83.5,81.1,80.4$, 73.7, 68.2, 67.0, 32.3, 31.0, 30.9, 30.08, 30.02, 29.9, 29.80, 29.77, 27.8, 27.5, 26.2, 23.1, 21.1, 20.1, 18.8, 14.5, -4.41, -4.45; HRMS (FAB, $\mathrm{M}+\mathrm{Na}^{+}$) calcd for $\mathrm{C}_{42} \mathrm{H}_{66} \mathrm{NaO}_{3} \mathrm{Si}_{2} 697.4448$, found 697.4431.

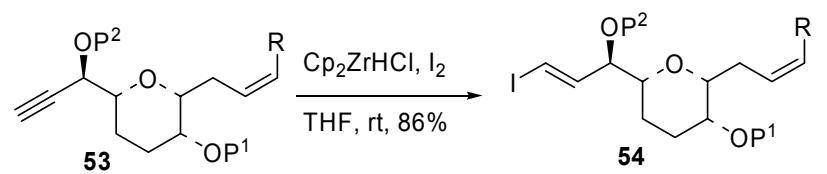

$(2 R, 3 R, 6 R)-6-\{(E)-(R)-1-\{[$ tert-Butyl(dimethyl)silyl] $0 x y\}-3-i o d o-a l l y l\}-3-\{[$ tert-

butyl(diphenyl)silyl]oxy\}-2-[(Z)-dodec-2-enyl]-tetrahydro-2H-pyran (54). To a stirred suspension of Schwartz reagent $(24 \mathrm{mg}, 0.092 \mathrm{mmol})$ in $\mathrm{CH}_{2} \mathrm{Cl}_{2}(1 \mathrm{~mL})$ was added alkyne $\mathbf{5 3}$ (52 $\mathrm{mg}, 0.0770 \mathrm{mmol})$ in $\mathrm{CH}_{2} \mathrm{Cl}_{2}(1.5 \mathrm{~mL})$. The resulting yellowish solution was stirred for $15 \mathrm{~min}$ and then cooled to $0{ }^{\circ} \mathrm{C}$. A solution of $\mathrm{I}_{2}$ in $\mathrm{CH}_{2} \mathrm{Cl}_{2}(0.2 \mathrm{M})$ was added until a brownish colour persisted ( $\sim 1$ equiv.). The reaction was stirred a further 10 min after which $\mathrm{Na}_{2} \mathrm{~S}_{2} \mathrm{O}_{3}(20 \%$, aq) was added. The brownish colour disappeared and the reaction mixture was partitioned between $\mathrm{CH}_{2} \mathrm{Cl}_{2}$ and $\mathrm{Na}_{2} \mathrm{~S}_{2} \mathrm{O}_{3}\left(20 \%\right.$, aq). The combined organic phases were dried $\left(\mathrm{MgSO}_{4}\right)$, filtered and concentrated in vacuo. Purification by flash chromatography (3.13-6.25\% EtOAc/heptane) afforded vinyl iodide 54 as a clear oil $(53 \mathrm{mg}, 86 \%)$ : $[\alpha]_{\mathrm{D}}^{23}+35.8\left(\mathrm{c}=1.0, \mathrm{CH}_{2} \mathrm{Cl}_{2}\right)$; IR (film) 3070 (w), 2927 (s), 2856 (s), 1608 (w), 1471 (m), 1427 (m), 1253 (m), 1110 (s), 863 (m), 701 (s); ${ }^{1} \mathrm{H}$ NMR $\left(500 \mathrm{MHz}, \mathrm{CDCl}_{3}\right) \delta$ 7.77-7.62 (m, 4H), 7.46-7.32 (m, 6H), 6.77 (dd, $J=14.4,4.5 \mathrm{~Hz}$, 
$1 \mathrm{H}), 6.30(\mathrm{dd}, J=14.4,1.6 \mathrm{~Hz}, 1 \mathrm{H}), 5.37-5.06(\mathrm{~m}, 2 \mathrm{H}), 4.23-4.18(\mathrm{~m}, 1 \mathrm{H}), 3.73-3.68(\mathrm{~m}, 1 \mathrm{H})$, 3.33-3.27 (m, 1H), $3.11(\mathrm{dd}, J=8.1,5.2 \mathrm{~Hz}, 1 \mathrm{H}), 2.36(\mathrm{td}, J=14.7,7.2,1 \mathrm{H}), 2.20-1.61(\mathrm{~m}, 6 \mathrm{H})$, 1.46-0.8 (m, 15H), $1.11(\mathrm{~s}, 9 \mathrm{H}), 0.94-0.86(\mathrm{~m}, 12 \mathrm{H}), 0.081(\mathrm{~s}, 3 \mathrm{H}), 0.077(\mathrm{~s}, 3 \mathrm{H}),{ }^{13} \mathrm{C}$ NMR $(125$ $\left.\mathrm{MHz}, \mathrm{CDCl}_{3}\right) \delta 145.7,136.0,134.4,134.1,131.2,129.5,129.4,127.4,126.1,80.5,79.7,76.6$, $76.2,67.8,31.9,30.57,30.52,29.65,29.60,29.3,27.4,27.2,25.8,22.7,19.68,19.63,18.2,14.1$, -4.8, -4.9; HRMS (FAB, M+Na ${ }^{+}$) calcd for $\mathrm{C}_{42} \mathrm{H}_{67} \mathrm{INaO}_{3} \mathrm{Si}_{2}$ 825.3571, found 825.3571.

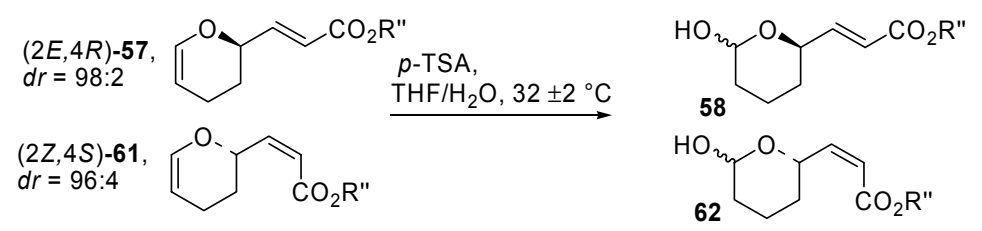

General procedure for preparation of hemiacetals 58 and 62. To a solution of vinyl ether 57 or 61 (or a mixture of the two) in THF $(0.02 \mathrm{M})$ was added $p$-toluenesulfonic acid monohydrate (5.0 equiv., $0.4 \mathrm{M}$ in water) dropwise over $30 \mathrm{~min}$ at $0{ }^{\circ} \mathrm{C}$. The resulting solution was heated at 32 $\pm 2{ }^{\circ} \mathrm{C},{ }^{5}$ and stirred for $20 \mathrm{~h}$. The reaction was quenched by addition of $\mathrm{NaOH}(2 \mathrm{M}$, aq) and partitioned between EtOAc and $\mathrm{NaOH}(2 \mathrm{M}$, aq) followed by repeated basic wash until the aqueous phase was clearly basic (tested with $\mathrm{pH}$ paper). The organic phase was dried $\left(\mathrm{MgSO}_{4}\right)$, filtered and concentrated in vacuo to afford a crude oil. Purification by flash chromatography (12.5-25\% EtOAc/heptane) afforded the hemiacetals (clear oils) as inseparable diastereomeric mixtures. Isolated yields were $81 \%$ from $\mathbf{5 8}, 89 \%$ from $\mathbf{6 2}$ and $85 \%$ from a mixture.

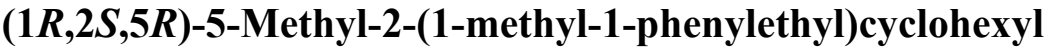
hydroxytetrahydro-2H-pyran-2-yl]acrylate (58). Diastereomeric ratio (major epimer/minor epimer $)=67: 33 ;[\alpha]_{\mathrm{D}}^{23}-0.75\left(\mathrm{c}=1.0, \mathrm{CH}_{2} \mathrm{Cl}_{2}\right)$; IR (film) $3411(\mathrm{br} \mathrm{s}), 2950(\mathrm{~s}), 2869(\mathrm{~m}), 1710$ (s), 1658 (m), 1442 (m), 1442 (m), 1297 (s), 1270 (s); ${ }^{1} \mathrm{H}$ NMR (400 MHz, CDCl 3 ) $\delta$ 7.28-7.18 $(\mathrm{m}, 4 \mathrm{H}), 7.13-7.03(\mathrm{~m}, 1 \mathrm{H}), 6.56-6.61(\mathrm{~m}, 1 \mathrm{H}), 5.60-5.46(\mathrm{~m}, 1 \mathrm{H}), 5.32(\mathrm{~s}, 1 \mathrm{H}$ major epimer), 
$4.83(\mathrm{dt}, J=10.7,4.4 \mathrm{~Hz}, 1 \mathrm{H}), 4.74$ (ddd, $J=9.3,2.0,6.3 \mathrm{~Hz}, 1 \mathrm{H}$ minor epimer), 4.50 (tdd, $J=$ 11.6, 2.0, 4.2, $1 \mathrm{H}$ major epimer), 4.00 (tdd, $J=11.4,4.1,2.0 \mathrm{~Hz}, 1 \mathrm{H}$ minor epimer), 2.84 (d, $J=$ $6.3 \mathrm{~Hz}, 1 \mathrm{H}$ minor epimer), 2.45 (dd, $J=3.0,1.9 \mathrm{~Hz}, 1 \mathrm{H}$ major epimer), 2.08-0.57 (m, 14H), 1.28 (s, 3H), $1.20(\mathrm{~s}, 3 \mathrm{H}), 0.83(\mathrm{~d}, J=6.5 \mathrm{~Hz}, 3 \mathrm{H}) ;{ }^{13} \mathrm{C} \mathrm{NMR}\left(100.6 \mathrm{MHz}, \mathrm{CDCl}_{3}\right) \delta$ 165.7, 165.6, $151.1,147.6,146.2,127.8,125.2,124.8,120.6,120.2,96.2,91.5,74.5,74.39,74.35,67.3,50.3$, $41.5,39.6,34.3,32.0,31.7,31.1,30.3,29.6,29.3,28.8,26.6,26.5,26.1,22.5,21.8,21.6,17.1$, 14.0; HRMS (FAB, $\mathrm{M}+\mathrm{Na}^{+}$) calcd for $\mathrm{C}_{24} \mathrm{H}_{34} \mathrm{O}_{4} \mathrm{Na} 409.2355$, found 409.2352 .

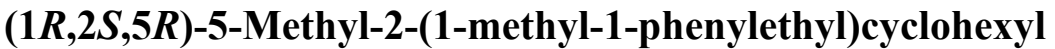

$(2 Z)-3-[(2 S, 6 R S)-6-$ hydroxytetrahydro-2H-pyran-2-yl]acrylate (62). Diastereomeric ratio (major epimer/minor epimer $)=67: 33 ;[\alpha]_{\mathrm{D}}{ }^{23}+14.5\left(\mathrm{c}=1.0, \mathrm{CH}_{2} \mathrm{Cl}_{2}\right)$; IR (film) $3407(\mathrm{br} \mathrm{s}), 2952(\mathrm{~s}), 2874(\mathrm{~s}), 1712$ (s), 1650 (m), 1415 (m), 1186 (s); ${ }^{1} \mathrm{H}$ NMR (400 MHz, $\left.\mathrm{CDCl}_{3}\right) \delta$ 7.31-7.19 (m, 4H), 7.16-7.08 (m, 1H), 6.05 (dd, J=11.7, 7.3 Hz, 1H major epimer), 5.97 (dd, J=11.7, $7.5 \mathrm{~Hz}, 1 \mathrm{H}$ minor epimer), 5.51-5.41 (m, 1H minor epimer), 5.29 (s, $1 \mathrm{H}$ minor epimer), 5.16-4.90 (m, 1H plus $1 \mathrm{H}$ major epimer), 4.88-4.66 (m, 1H plus 1H major epimer), 3.58 (br s, $1 \mathrm{H}$ major epimer), 2.86 (br s, $1 \mathrm{H}$ minor epimer), $2.08-0.56(\mathrm{~m}, 23 \mathrm{H}) ;{ }^{13} \mathrm{C} \mathrm{NMR}\left(100.6 \mathrm{MHz}, \mathrm{CDCl}_{3}\right) \delta 165.3,165.2,151.8,149.5$, $148.7,128.4,125.85,125.81,125.5,120.2,119.8,96.3,92.1,74.7,74.6,74.1,66.8,50.9,42.1$, $40.17,40.11,34.9,32.6,32.3,31.8,30.5,29.8,29.6,29.4,28.1,27.9,27.08,27.05,25.9,25.6$, 23.1, 22.5, 22.2, 17.5, 14.5; HRMS (FAB, $\mathrm{M}+\mathrm{H}^{+}$) calcd for $\mathrm{C}_{24} \mathrm{H}_{35} \mathrm{O}_{4} 387.2535$, found 387.2547.

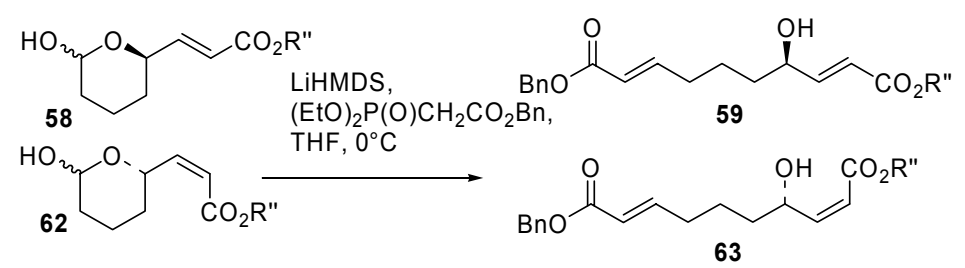


General procedure for HWE reactions with hemiacetals 59 and 63. To a solution of $(\mathrm{EtO}){ }_{2} \mathrm{P}(\mathrm{O}) \mathrm{CH}_{2} \mathrm{CO}_{2} \mathrm{Bn}^{6}$ (5.0 equiv., $0.4 \mathrm{M}$ ) in THF at $0{ }^{\circ} \mathrm{C}$ was added LiHMDS (1.5 equiv., 1.0 $\mathrm{M}$ in toluene). After $1 \mathrm{~h}$ the resulting solution was transferred via a cannula to a precooled solution of hemiacetal $\mathbf{5 7}$ or $\mathbf{6 2}$ (or a mixture of the two) in THF (1.0 equiv., $0.1 \mathrm{M}$ ) and stirred at this temperature for $14 \mathrm{~h}$. The reaction was then quenched with phosphate buffer $(\mathrm{pH} \mathrm{7)}$ and partitioned between EtOAc and phosphate buffer $(\mathrm{pH} 7)$. The combined organic phases were dried $\left(\mathrm{MgSO}_{4}\right)$, filtered and concentrated in vacuo to afford a crude oil. Purification by flash chromatography (12.5-25\% EtOAc/heptane) furnished the olefinated product as a clear oil. Isolated yields were $81 \%$ from 59, 74\% from $\mathbf{6 3}$ and $80 \%$ from a mixture.

\section{0-Benzyl 1-[(1R,2S,5R)-5-methyl-2-(1-methyl-1-phenylethyl)cyclohexyl] $\quad(2 E, 4 R, 8 E)-4-$} hydroxydeca-2,8-dienedioate (59). $[\alpha]_{\mathrm{D}}^{23}+1.5\left(\mathrm{c}=1.0, \mathrm{CH}_{2} \mathrm{Cl}_{2}\right.$ ); IR (film) 3455 (br, s), 2952 (s), 2919 (s), 1714 (s), 1652 (s), 1267 (m), 1174 (m); ${ }^{1} \mathrm{H}$ NMR (500 MHz, $\mathrm{CDCl}_{3}$ ) $\delta$ 7.38-7.29 (m, 5H), 7.29-7.20 (m, 5H), 7.12-7.05 (m, 1H), $6.99(\mathrm{td}, J=15.6,6.9 \mathrm{~Hz}, 1 \mathrm{H}), 6.51(\mathrm{dd}, J=15.7$, $5.3 \mathrm{~Hz}, 1 \mathrm{H}), 5.89$ (td, $J=15.5,1.4 \mathrm{~Hz}, 1 \mathrm{H}), 5.39(\mathrm{dd}, J=15.7,1.5 \mathrm{~Hz}, 1 \mathrm{H}), 5.30(\mathrm{~s}, 1 \mathrm{H}), 5.17,(\mathrm{~s}$, 2H), 4.85 (dt, $J=10.6,4.2 \mathrm{~Hz}, 1 \mathrm{H}), 4.16$ (br s, 1H), 2.24 (dd, $J=12.4,6.3 \mathrm{~Hz}, 2 \mathrm{H}), 2.11-1.99$ $(\mathrm{m}, 1 \mathrm{H}), 1.94-1.08(\mathrm{~m}, 1 \mathrm{H}), 1.79-0.79(\mathrm{~m}, 9 \mathrm{H}), 1.29(\mathrm{~s}, 3 \mathrm{H}), 1.20(\mathrm{~s}, 3 \mathrm{H}), 0.87(\mathrm{~d}, J=6.5 \mathrm{~Hz}$ $\left.{ }^{3 H}\right) ;{ }^{13} \mathrm{C} \mathrm{NMR}\left(125 \mathrm{MHz}, \mathrm{CDCl}_{3}\right) \delta 166.7,165.8,152.2,149.4,148.9,136.5,128.9,128.6$, $128.5,128.3,125.8,125.1,121.9,121.4,74.8,71.2,66.5,50.8,42.0,40.1,36.1,34.9,32.3,31.7$, 30.1, 28.4, 26.9, 25.2, 24.0, 22.2; HRMS (FAB, $\mathrm{M}+\mathrm{H}^{+}$) calcd for $\mathrm{C}_{33} \mathrm{H}_{43} \mathrm{O}_{5}$ 519.3110, found 519.3114

10-Benzyl 1-[(1R,2S,5R)-5-methyl-2-(1-methyl-1-phenylethyl)cyclohexyl] $\quad(2 Z, 4 S, 8 E)-4-$ hydroxydeca-2,8-dienedioate (63). $[\alpha]_{\mathrm{D}}^{23}+3.1\left(\mathrm{c}=1.0, \mathrm{CH}_{2} \mathrm{Cl}_{2}\right)$; IR (film) 3440 (br, m), 2950 (s), 2923 (s), 1712 (s), 1650 (m), 1182 (s); ${ }^{1} \mathrm{H}$ NMR (500 MHz, CDCl $)$ ઈ 7.42-7.32 (m, 4H), 
7.31-7.23 (m, 5H), 7.17-7.10 (m, 1H), $7.05(\mathrm{td}, J=15.6,6.9 \mathrm{~Hz}, 1 \mathrm{H}), 6.04(\mathrm{dd}, J=11.9,6.9 \mathrm{~Hz}$, 1H), $5.92(\mathrm{td}, J=15.7,1.3 \mathrm{~Hz}, 1 \mathrm{H}), 5.32(\mathrm{~s}, 1 \mathrm{H}), 5.21-5.16(\mathrm{~m}, 1 \mathrm{H}), 5.19(\mathrm{~s}, 2 \mathrm{H}), 4.84(\mathrm{dt}, J=$ 10.8, 4.4 Hz, 1H), 4.74 (dd, $J=11.9,6.5 \mathrm{~Hz}, 1 \mathrm{H}), 3.27$ (br s, 1H), 2.29 (q, $J=6.6 \mathrm{~Hz}, 2 \mathrm{H}$ ), 2.06 (ddd, $J=12.6,10.9,3.7 \mathrm{~Hz}, 1 \mathrm{H}) ; 1.79-0.80(\mathrm{~m}, 10 \mathrm{H}), 1.30(\mathrm{~s}, 3 \mathrm{H}), 1.20(\mathrm{~s}, 3 \mathrm{H}), 0.87(\mathrm{~d}, J=$ $6.5 \mathrm{~Hz}, 3 \mathrm{H}) ;{ }^{13} \mathrm{C}$ NMR $\left(125 \mathrm{MHz}, \mathrm{CDCl}_{3}\right) \delta 166.4,165.9,151.5,151.0,149.5,128.5,128.1$, $128.0,127.9,125.3,124.9,121.2,121.0,74.8,67.6,66.0,50.5,41.6,39.6,35.7,34.5,32.0,31.3$, 28.0, 26.5, 24.7, 23.7, 21.7; HRMS (FAB, $\mathrm{M}+\mathrm{H}^{+}$) calcd for $\mathrm{C}_{33} \mathrm{H}_{43} \mathrm{O}_{5}$ 519.3110, found 519.3114.

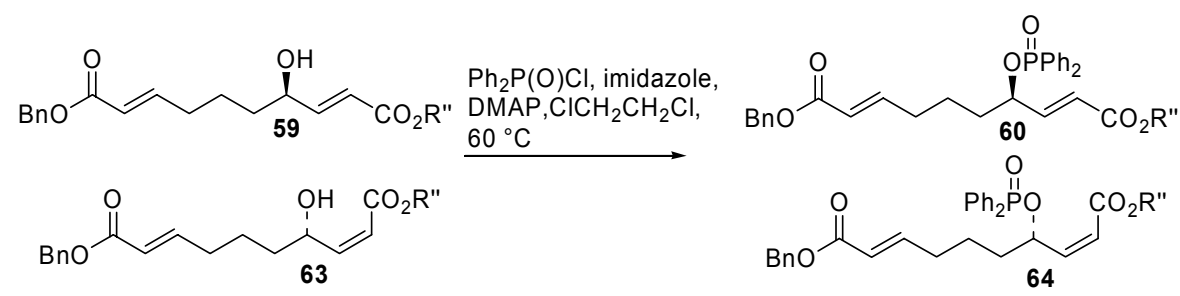

General procedure for the preparation of diphenylphosphinate esters 60 and 64 . To a stirred solution of $\mathbf{5 9}$ or $\mathbf{6 3}$ (or a mixture of the two) in DCE/THF (0.1 M, 1:1) was added imidazole (5 equiv.) followed by dropwise addition of diphenylphosphinic chloride (3 equiv.) at room temperature. The resulting slurry was stirred at $60{ }^{\circ} \mathrm{C}$ for $16 \mathrm{~h}$, then quenched with phosphate buffer ( $\mathrm{pH}$ 7) and partitioned between $\mathrm{CH}_{2} \mathrm{Cl}_{2}$ and phosphate buffer $(\mathrm{pH}$ 7). The combined organic phases were dried $\left(\mathrm{MgSO}_{4}\right)$, filtered and concentrated in vacuo to afford a crude oil. Purification by flash chromatography (25-37.5\% EtOAc/heptane) afforded the phosphinate esters. Isolated yields were $91 \%$ from $\mathbf{6 0}, 86 \%$ from $\mathbf{6 4}$ and $96 \%$ from a mixture.

\section{0-Benzyl 1-[(1R,2S,5R)-5-methyl-2-(1-methyl-1-phenylethyl)cyclohexyl] $\quad(2 E, 4 R, 8 E)-4-$}

[(diphenylphosphoryl)oxy]deca-2,8-dienedioate (60). $[\alpha]_{\mathrm{D}}^{23}+34.8\left(\mathrm{c}=1.0, \mathrm{CH}_{2} \mathrm{Cl}_{2}\right)$; IR (film) 3060 (m), 2952 (s), 2925 (s), 1714 (s), 1654 (m), 1438 (m); ${ }^{1} \mathrm{H}$ NMR (500 MHz, $\left.\mathrm{CDCl}_{3}\right) \delta 7.82-$ $7.70(\mathrm{~m}, 4 \mathrm{H}), 7.56-7.14(\mathrm{~m}, 16 \mathrm{H}), 7.00(\mathrm{t}, J=7.1 \mathrm{~Hz}, 1 \mathrm{H}), 6.92(\mathrm{td}, J=15.4,6.9 \mathrm{~Hz}, 1 \mathrm{H}), 6.51$ (dd, $J=15.7,5.9 \mathrm{~Hz}, 1 \mathrm{H}), 5.82(\mathrm{~d}, J=15.6 \mathrm{~Hz}, 1 \mathrm{H}), 5.37(\mathrm{dd}, J=15.6,0.9 \mathrm{~Hz}, 1 \mathrm{H}), 5.16(\mathrm{~s}, 2 \mathrm{H})$, 
$4.93(\mathrm{qd}, J=12.4,6.1 \mathrm{~Hz}, 1 \mathrm{H}), 4.82(\mathrm{dt}, J=10.6,4.3 \mathrm{~Hz}, 1 \mathrm{H}), 2.17(\mathrm{q}, J=7.1 \mathrm{~Hz}, 2 \mathrm{H}), 2.03-$ $1.95(\mathrm{~m}, 1 \mathrm{H}), 1.86(\mathrm{~d}, J=12.4 \mathrm{~Hz}, 1 \mathrm{H}), 1.80-0.74(\mathrm{~m}, 9 \mathrm{H}), 1.27(\mathrm{~s}, 3 \mathrm{H}), 1.20(\mathrm{~s}, 3 \mathrm{H}), 0.87(\mathrm{~d}, J=$ 6.5 Hz, 3H); ${ }^{13} \mathrm{C}$ NMR (125 MHz, $\left.\mathrm{CDCl}_{3}\right) \delta 166.6,165.3,151.7,149.1,144.9,144.8,136.4$, $132.8,132.7,132.2,132.1,131.8,131.7,129.0,128.91,128.87,128.8,128.6,128.5,128.3$, $125.8,125.4,123.2,121.9,75.1,74.5,74.4,66.5,50.8,42.0,40.1,35.4,35.4,34.9,32.1,31.7$, 27.5, 27.0, 26.3, 23.1, 22.2; HRMS (FAB, $\left.\mathrm{M}+\mathrm{H}^{+}\right)$calcd for $\mathrm{C}_{45} \mathrm{H}_{52} \mathrm{O}_{6} \mathrm{P}$ 719.3502, found 719.3527.

10-Benzyl 1-[(1R,2S,5R)-5-methyl-2-(1-methyl-1-phenylethyl)cyclohexyl] $\quad(2 Z, 4 S, 8 E)-4-$ [(diphenylphosphoryl)oxy]deca-2,8-dienedioate (64). $[\alpha]_{\mathrm{D}}^{23}+1.2\left(\mathrm{c}=1.0, \mathrm{CH}_{2} \mathrm{Cl}_{2}\right)$; IR (film) 3058 (m), 2952 (s), 2925 (s), 1714 (s), 1652 (m), 1440 (m), 1230 (s), 1199 (s); ${ }^{1} \mathrm{H}$ NMR (500 $\left.\mathrm{MHz}, \mathrm{CDCl}_{3}\right) \delta$ 7.87-7.72 (m, 4H), 7.50-7.16 (m, 16H), 7.13-7.07 (m, 1H), $7.02(\mathrm{td}, J=15.4,6.8$ $\mathrm{Hz}, 1 \mathrm{H}), 6.13(\mathrm{dd}, J=11.6,7.9 \mathrm{~Hz}, 1 \mathrm{H}), 5.90$ (d, $J=15.6 \mathrm{~Hz}, 1 \mathrm{H}), 5.92-5.83(\mathrm{~m}, 1 \mathrm{H}), 5.18$ (s, 2H), $4.95(\mathrm{~d}, J=11.6 \mathrm{~Hz}, 1 \mathrm{H}), 4.68(\mathrm{dt}, J=10.6,4.3 \mathrm{~Hz}, 1 \mathrm{H}), 2.24(\mathrm{q}, J=7.0 \mathrm{~Hz}, 2 \mathrm{H}), 2.03-1.85$ $(\mathrm{m}, 2 \mathrm{H}), 1.82-0.78(\mathrm{~m}, 9 \mathrm{H}), 1.24(\mathrm{~s}, 3 \mathrm{H}), 1.18(\mathrm{~s}, 3 \mathrm{H}), 0.91(\mathrm{~d}, J=6.5 \mathrm{~Hz}, 3 \mathrm{H}) ;{ }^{13} \mathrm{C}$ NMR $(125$ $\left.\mathrm{MHz}, \mathrm{CDCl}_{3}\right) \delta 166.7,164.6,151.8,149.7,147.6,147.5,136.5,132.58,132.54,132.52,132.2$, $132.1,132.0,131.9,131.5,131.4,128.9,128.86,128.84,128.7,128.6,128.5,128.3,125.7$, $125.4,121.7,120.6,74.6,73.09,73.05,66.4,50.8,42.0,40.0,35.76,35.72,34.9,32.1,31.6$, 28.3, 26.9, 25.3, 23.7, 22.3; HRMS (FAB, $\left.\mathrm{M}+\mathrm{H}^{+}\right)$calcd for $\mathrm{C}_{45} \mathrm{H}_{52} \mathrm{O}_{6} \mathrm{P}$ 719.3502, found 719.3506 .

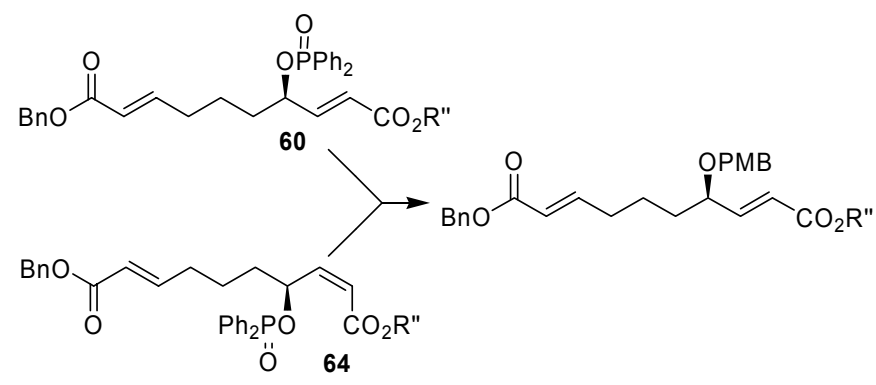




\section{0-Benzyl 1-[(1R,2S,5R)-5-methyl-2-(1-methyl-1-phenylethyl)cyclohexyl] $\quad(2 E, 4 R, 8 E)-4-[4-$}

methoxybenzyloxy]deca-2,8-dienedioate (66). Neocuproine (1.18 $\mathrm{mg}, 0.0057 \mathrm{mmol})$ and $\mathrm{Pd}_{2} \mathrm{dba}_{3}(1.46 \mathrm{mg}, 0.0014 \mathrm{mmol})$ were dissolved in $\mathrm{CH}_{2} \mathrm{Cl}_{2}(100 \mu \mathrm{L})$ at rt and stirred for 30 minutes. The resulting clear orange-red solution was transferred to a stirred solution of a mixture of 60 and $64(20 \mathrm{mg}, 0.028 \mathrm{mmol})$ in 4-methoxybenzyl alcohol $(300 \mu \mathrm{L})$ and $\mathrm{CH}_{2} \mathrm{Cl}_{2}(200 \mu \mathrm{L})$ at rt. The resulting clear yellow solution was stirred at $\mathrm{rt}$ for $3 \mathrm{~h}$ during which time the color changed to light brown. The reaction mixture was poured onto phosphate buffer $(\mathrm{pH} 7)$ and partitioned between $\mathrm{CH}_{2} \mathrm{Cl}_{2}$ and phosphate buffer $(\mathrm{pH}$ 7). The combined organic phases were dried $\left(\mathrm{MgSO}_{4}\right)$ followed by removal of $\mathrm{CH}_{2} \mathrm{Cl}_{2}$ under reduced pressure. Purification by flash chromatography (6.25-12.5\% EtOAc/heptane) furnished the $(2 E, 8 E)$-diene 66 as a clear oil (16 mg, 89\%): Diastereomeric ratio $(4 R):(4 S)=97: 3$ separable by flash chromatography: $[\alpha]_{\mathrm{D}}{ }^{23}$ +26.0 (c = 0.45, $\mathrm{CH}_{2} \mathrm{Cl}_{2}$ ); IR (film) 3056 (w), 2952 (s), 2867 (s), 1714 (s), 1652 (m), 1249 (s), 1033 (s); ${ }^{1} \mathrm{H}$ NMR (500 MHz, $\left.\mathrm{CDCl}_{3}\right) \delta$ 7.42-7.32 (m, 4H), 7.32-7.20 (m, 9H), 7.09-7.03 (m, 1H), 7.01-6.93 (m, 1H), $6.87(\mathrm{~d}, J=8.6 \mathrm{~Hz}, 2 \mathrm{H}), 6.53(\mathrm{dd}, J=15.7,6.6 \mathrm{~Hz}, 1 \mathrm{H}), 5.85(\mathrm{~d}, J=$ $15.5 \mathrm{~Hz}, 1 \mathrm{H}), 5.44(\mathrm{dd}, J=15.7,0.8 \mathrm{~Hz}, 1 \mathrm{H}), 5.17(\mathrm{~s}, 2 \mathrm{H}), 4.88(\mathrm{dt}, J=11.1,4.9 \mathrm{~Hz}, 1 \mathrm{H}), 4.45$ $(\mathrm{d}, J=11.8 \mathrm{~Hz}, 1 \mathrm{H}), 4.19(\mathrm{~d}, J=11.5 \mathrm{~Hz}, 1 \mathrm{H}), 3.81-3.76(\mathrm{~m}, 4 \mathrm{H}), 2.16(\mathrm{dd}, J=13.4,6.9 \mathrm{~Hz}$, 2H), 2.05 (dt, $J=11.8,2.8 \mathrm{~Hz}, 1 \mathrm{H}), 1.93$ (d, $J=13.4 \mathrm{~Hz}, 1 \mathrm{H}), 1.75-0.80(\mathrm{~m}, 9 \mathrm{H}), 1.32(\mathrm{~s}, 3 \mathrm{H})$, $1.23(\mathrm{~s}, 3 \mathrm{H}), 0.88(\mathrm{~d}, J=6.5 \mathrm{~Hz}, 3 \mathrm{H}) ;{ }^{13} \mathrm{C} \mathrm{NMR}\left(125 \mathrm{MHz}, \mathrm{CDCl}_{3}\right) \delta 166.3,165.3,159.2,151.4$, $149.2,147.3,136.1,130.0,129.3,128.5,128.19,128.14,127.8,125.4,125.0,122.7,121.3$, $113.8,74.6,70.6,66.0,55.2,50.4,41.7,39.7,34.5,34.3,31.9,31.3,27.4,26.6,25.5,23.6,21.7$; HRMS (FAB, $\mathrm{M}+\mathrm{H}^{+}$) calcd for $\mathrm{C}_{41} \mathrm{H}_{51} \mathrm{O}_{6} 639.3686$ found 639.3697 . 
(1)

(4R)-4-[2-(Trimethylsilyl)ethoxy]decanedioic acid 1-[(1R,2S,5R)-5-methyl-2-(1-methyl-1phenylethyl)cyclohexyl] ester (69). To a solution of diene 65 (20.0 $\mathrm{mg}, 0.032 \mathrm{mmol})$ in hexanes (2.5 mL) was added palladium (10 wt. \% on activated carbon, cat.) under a nitrogen atmosphere and the atmosphere was then changed to hydrogen (purged 5 times). After $48 \mathrm{~h}$ at $\mathrm{rt}$, the reaction was passed through a short plug of celite and concentrated in vacuo. Purification by flash chromatography (12.5-25\% EtOAc/heptane) furnished the saturated acid $\mathbf{6 9}$ as a clear oil (15.3 mg, 90\%): $[\alpha]_{\mathrm{D}}^{23}+0.15$ (c = 1.0, $\mathrm{CH}_{2} \mathrm{Cl}_{2}$ ); IR (film) 3058 (br, m), 2950 (s), 2923 (s), 1727 (s), 1710 (s); 1247 (s), 1174 (s), 1091 (s); ${ }^{1} \mathrm{H}$ NMR (500 MHz, $\mathrm{CDCl}_{3}$ ) $\delta$ The acid proton is not reported, 7.31-7.22 (m, 4H), 7.15-7.08 (m, 1H), $4.81(\mathrm{dt}, J=10.7,4.5 \mathrm{~Hz}, 1 \mathrm{H}), 3.48-3.36(\mathrm{~m}$, 2H), 3.14-3.05 (m, 1H), $2.35(\mathrm{t}, J=7.5 \mathrm{~Hz}, 2 \mathrm{H}), 2.03-1.96(\mathrm{~m}, 1 \mathrm{H}), 1.92-1.80(\mathrm{~m}, 2 \mathrm{H}), 1.79-0.75$ $(\mathrm{m}, 19 \mathrm{H}), 1.30(\mathrm{~s}, 3 \mathrm{H}), 1.20(\mathrm{~s}, 3 \mathrm{H}), 0.85(\mathrm{~d}, J=6.4 \mathrm{~Hz}, 3 \mathrm{H}), 0.00(\mathrm{~s}, 9 \mathrm{H}) ;{ }^{13} \mathrm{C} \mathrm{NMR}(125 \mathrm{MHz}$, $\left.\mathrm{CDCl}_{3}\right) \delta 179.2,173.0,151.68,151.62,127.8,125.3,124.9,77.8,73.9,65.9,50.3,41.8,39.7$, 34.5, 33.8, 33.6, 31.2, 30.2, 29.2, 28.6, 27.7, 26.5, 25.1, 25.0, 24.6, 21.7, 18.6, -1.3; HRMS (FAB, $\mathrm{M}+\mathrm{H}^{+}$) calcd for $\mathrm{C}_{31} \mathrm{H}_{53} \mathrm{O}_{5} \mathrm{Si}$ 533.3662, found 533.3663.

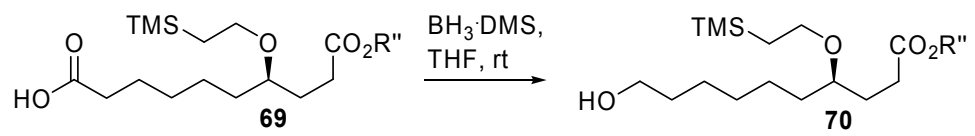

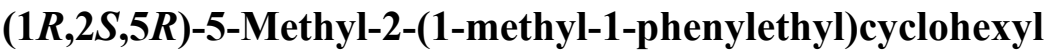

(4R)-10-hydroxy-4-[2(trimethylsilyl)ethoxy]decanoate (83). To a solution of 69 (475 mg, $0.029 \mathrm{mmol})$ in THF (10 $\mathrm{mL})$ at $0{ }^{\circ} \mathrm{C}$ was added $\mathrm{BH}_{3} \cdot \mathrm{DMS}\left(90 \mu \mathrm{L}, 0.09 \mathrm{mmol}, 1.0 \mathrm{M}\right.$ in $\left.\mathrm{CH}_{2} \mathrm{Cl}_{2}\right)$. The temperature was raised to rt over $12 \mathrm{~h}$ and the reaction was quenched by careful addition of phosphate buffer $(\mathrm{pH}$ 7). The resulting solution was partitioned between EtOAc and phosphate buffer ( $\mathrm{pH} 7)$. The combined organic phases were dried $\left(\mathrm{MgSO}_{4}\right)$, filtered and concentrated in vacuo to afford a 
crude oil. Purification by flash chromatography (12.5-25\% EtOAc/heptane) furnished the reduced product 83 as a clear oil (460 mg, quant.): $[\alpha]_{\mathrm{D}}{ }^{23}-1.32\left(\mathrm{c}=0.87, \mathrm{CH}_{2} \mathrm{Cl}_{2}\right)$; IR (film) 3429 (br, s), 2938 (s), 2856 (s), 1727 (s), 1456 (m), 1248 (m), 1177 (m), 1091 (m); ${ }^{1} \mathrm{H}$ NMR (500 MHz, $\left.\mathrm{CDCl}_{3}\right) \delta 7.31-7.24(\mathrm{~m}, 4 \mathrm{H}), 7.15-7.10(\mathrm{~m}, 1 \mathrm{H}), 4.81(\mathrm{dt}, J=10.7,4.5 \mathrm{~Hz}, 1 \mathrm{H}), 3.64(\mathrm{t}, J=6.6$ $\mathrm{Hz}, 2 \mathrm{H}), 3.48-3.37$ (m, 2H), 3.14-3.06 (m, 1H), 2.05-1.94 (m, 1H), 1.94-1.79 (m, 2H), 1.78-0.77 $(\mathrm{m}, \mathrm{H}), 1.31(\mathrm{~s}, 3 \mathrm{H}), 1.20(\mathrm{~s}, 3 \mathrm{H}), 0.00(\mathrm{~s}, 9 \mathrm{H}) ;{ }^{13} \mathrm{C} \mathrm{NMR}\left(125 \mathrm{MHz}, \mathrm{CDCl}_{3}\right) \delta$ 173.1, 151.6, $127.8,125.3,124.9,77.8,73.9,65.9,63.0,50.3,41.7,39.6,34.5,33.7,32.7,31.2,30.2,29.5$, 28.6, 27.7, 26.5, 25.7, 25.3, 25.1, 21.7, 18.6, -1.3; HRMS (FAB, M+ $\mathrm{H}^{+}$) calcd for $\mathrm{C}_{31} \mathrm{H}_{55} \mathrm{O}_{4} \mathrm{Si}$ 519.3870, found 519.3873.

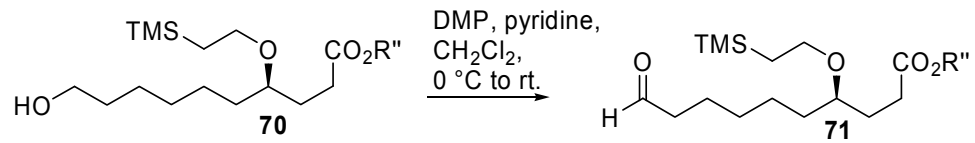

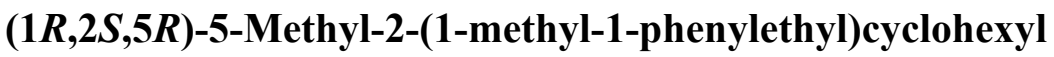

(4R)-10-0xo-4-[2(trimethylsilyl)ethoxy]decanoate (70). Dess-Martin periodinane (508 $\mathrm{mg}, 1.20 \mathrm{mmol}$ ) was added in one portion to a solution of $\mathbf{8 3}(478 \mathrm{mg}, 0.92 \mathrm{mmol})$ and pyridine $(15 \mu \mathrm{L}, 0.18 \mathrm{mmol})$ in $\mathrm{CH}_{2} \mathrm{Cl}_{2}(8 \mathrm{~mL})$ at $0{ }^{\circ} \mathrm{C}$. The resulting suspension was stirred for $4 \mathrm{~h}$ followed by addition of $\mathrm{NaOH}$ (2 M, aq). After stirring for an additional 5 min the reaction was partitioned between $\mathrm{CH}_{2} \mathrm{Cl}_{2}$ and water. The combined organic phases were dried $\left(\mathrm{MgSO}_{4}\right)$, filtered and concentrated in vacuo to afford a crude oil. Purification by flash chromatography (6.25\% EtOAc/heptane) afforded aldehyde 70 as a clear oil $(392 \mathrm{mg}, 82 \%)$ : $[\alpha]_{\mathrm{D}}{ }^{23}-1.2\left(\mathrm{c}=1.0, \mathrm{CH}_{2} \mathrm{Cl}_{2}\right)$; IR (film) 2950 (s), 2929 (s), 2863 (m), 1727 (s), 1247 (m), 1174 (m), 1089 (m); ${ }^{1} \mathrm{H}$ NMR (400 MHz, CDCl $) \delta$ $9.80(\mathrm{t}, J=1.8 \mathrm{~Hz}, 1 \mathrm{H}), 7.32-7.27(\mathrm{~m}, 4 \mathrm{H}), 7.15(\mathrm{~m}, 1 \mathrm{H}), 4.84(\mathrm{dt}, J=10.7,4.4 \mathrm{~Hz}, 1 \mathrm{H}), 3.44(\mathrm{~m}$, 2H), $3.13(\mathrm{~m}, 1 \mathrm{H}), 2.46(\mathrm{dt}, J=7.3,1.8 \mathrm{~Hz}, 1 \mathrm{H}), 2.02(\mathrm{~m}, 1 \mathrm{H}), 1.96-1.83(\mathrm{~m}, 2 \mathrm{H}), 1.82-0.81(\mathrm{~m}$, 23H), $1.34(\mathrm{~s}, 3 \mathrm{H}), 1.23(\mathrm{~s}, 3 \mathrm{H}), 0.03(\mathrm{~s}, 9 \mathrm{H}) ;{ }^{13} \mathrm{C} \mathrm{NMR}\left(100.6 \mathrm{MHz}, \mathrm{CDCl}_{3}\right) \delta$ 203.1, 173.4, $152.0,128.2,125.8,125.4,78.2,74.4,66.4,50.7,44.2,42.2,40.1,34.9,34.1,32.3,31.7,30.6$, 
29.7, 29.1, 28.1, 27.0, 25.6, 25.5, 23.1, 22.4, 22.2, 19.0, 14.5, -0.9; HRMS (ES+, M+Na $\left.{ }^{+}\right)$calcd for $\mathrm{C}_{31} \mathrm{H}_{52} \mathrm{NaO}_{4} \mathrm{Si}$ 539.3532, found 539.3533.

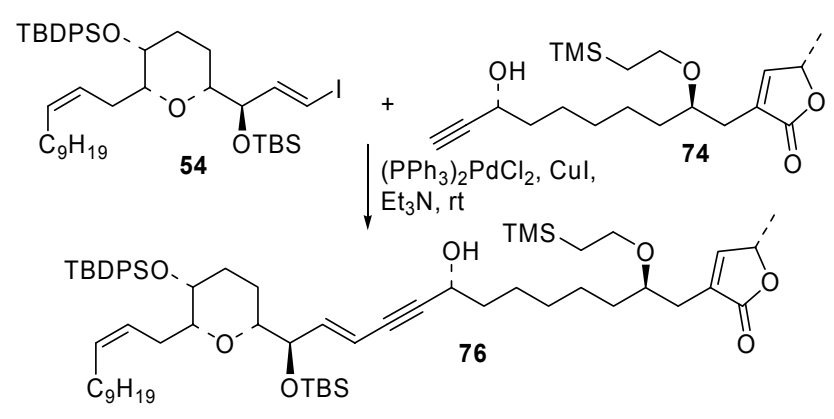

$(5 S)-3-\{(2 R, 8 R, 11 E, 13 R)-13-\{[t e r t-B u t y l(d i m e t h y l) \operatorname{silyl}] 0 x y\}-13-\{(2 R, 5 R, 6 R)-5-\{[t e r t-$

butyl(diphenyl)silyl]oxy\}-6-[(E)-dodec-2-en-1-yl]tetrahydro-2H-pyran-2-yl\}-8-hydroxy-2-[2(trimethylsilyl)ethoxy]tridec-11-en-9-yn-1-yl\}-5-methylfuran-2(5H)-one (76). To a solution of vinyl iodide $54(26.3 \mathrm{mg}, 0.033 \mathrm{mmol})$ in $\mathrm{Et}_{3} \mathrm{~N}(0.5 \mathrm{~mL})$ was added $\mathrm{CuI}(1.29 \mathrm{mg}, 0.0068 \mathrm{mmol})$ and dichlorobis(triphenylphosphine)-palladium(II) (1.91 mg, $0.0027 \mathrm{mmol})$. The reaction mixture was stirred for $35 \mathrm{~min}$ at rt, after which a solution of acetylene $74(12 \mathrm{mg}, 0.0328 \mathrm{mmol})$ in $\mathrm{Et}_{3} \mathrm{~N}$ $(1 \mathrm{~mL})$ was added dropwise over $10 \mathrm{~min}$ (rinsed with $0.5 \mathrm{~mL} \mathrm{Et}{ }_{3} \mathrm{~N}$ ). After $2.5 \mathrm{~h}$, the volatiles were removed in vacuo. Purification by flash chromatography (12.5-25\% EtOAc/heptane) afforded ene-yne 76 as a yellowish oil $(30.4 \mathrm{mg}, 89 \%)$ : $[\alpha]_{\mathrm{D}}{ }^{23}+36.4\left(\mathrm{c}=1.0, \mathrm{CH}_{2} \mathrm{Cl}_{2}\right)$; IR (film) 3436 (br, s), 2929 (s), 2856 (s), 1758 (m), 1249 (m), 1103 (s), 1027 (m), 836 (m); 703 (m); ${ }^{1} \mathrm{H}$ NMR (500 MHz, $\left.\mathrm{CDCl}_{3}\right) \delta$ 7.76-7.60 (m, 4H), 7.46-7.31 (m, 6H), $7.13(\mathrm{~d}, J=1.1 \mathrm{~Hz}, 1 \mathrm{H}), 6.36$ (dd, $J=15.9,4.2 \mathrm{~Hz}, 1 \mathrm{H}), 5.81(\mathrm{td}, J=16.0,1.8 \mathrm{~Hz}, 1 \mathrm{H}), 5.36-5.13(\mathrm{~m}, 2 \mathrm{H}), 5.05-4.96(\mathrm{~m}, 1 \mathrm{H})$, 4.50-4.42 (m, 1H), 4.32-4.25 (m, 1H), 3.73-3.68 (m, 1H), 3.56-3.42 (m, 3H), 3.31 (ddd, $J=11.4$, $5.8,1.7 \mathrm{~Hz}, 1 \mathrm{H}), 3.10(\mathrm{dd}, J=8.0,5.6 \mathrm{~Hz}, 1 \mathrm{H}), 2.43(\mathrm{~d}, J=5.4 \mathrm{~Hz}, 2 \mathrm{H}), 2.39-2.26(\mathrm{~m}, 1 \mathrm{H}), 1.54-$ $0.70(\mathrm{~m}, 35 \mathrm{H}), 1.40(\mathrm{~d}, J=6.8 \mathrm{~Hz}, 3 \mathrm{H}), 1.09$ (s, 9H), 0.90 (s, 9H), $0.08(\mathrm{~s}, 6 \mathrm{H}), 0.00(\mathrm{~s}, 9 \mathrm{H}) ;{ }^{13} \mathrm{C}$ NMR $\left(125 \mathrm{MHz}, \mathrm{CDCl}_{3}\right) \delta 173.9,151.3,143.6,136.0,134.4,134.1,131.2,130.7,129.5,129.4$, $127.4,126.0,109.0,90.1,83.5,80.4,80.1,77.4,74.1,67.8,66.3,62.9,37.8,34.0,31.9,30.5$, 
$29.8,29.6,29.5,29.4,29.35,29.32,27.3,27.1,25.8,25.2,25.1,22.6,19.6,19.1,18.6,18.2,14.1$, -1.3, -4.82, -4.89; HRMS (FAB, M+Na+) calcd for $\mathrm{C}_{62} \mathrm{H}_{100} \mathrm{NaO}_{7} \mathrm{Si}_{3}$ 1063.6675, found 1063.6689.

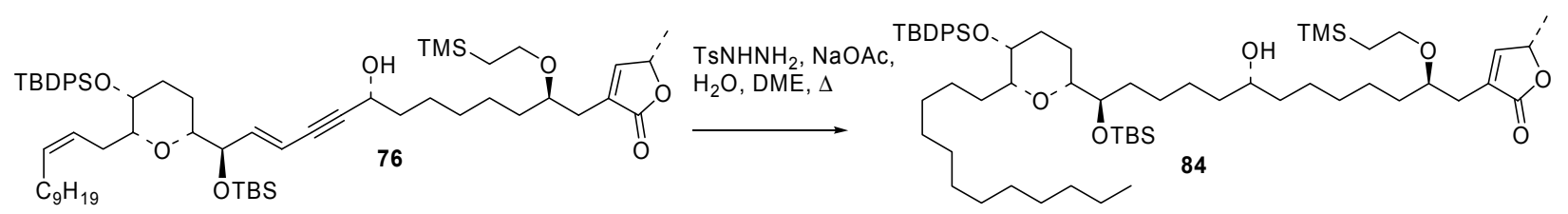

$(5 S)-3-\{(2 R, 8 R, 13 R)-13-\{[$ tert-Butyl(dimethyl)silyl] $0 x y\}-13-[(2 R, 5 R, 6 R)-5-\{[t e r t-$

butyl(diphenyl)silyl]oxy\}-6-dodecyltetrahydro-2H-pyran-2-yl)-8-hydroxy-2-[2-

(trimethylsilyl)ethoxy]tridecyl\}-5-methylfuran-2(5H)-one (84). A solution of ene-yne 76 (17.5

$\mathrm{mg}, 0.017 \mathrm{mmol})$ and tosylhydrazine $(300 \mathrm{mg}, 1.6 \mathrm{mmol})$ in 1,2-DME $(2.4 \mathrm{~mL})$ was heated to reflux and sodium acetate $(160 \mathrm{mg}, 2.0 \mathrm{mmol})$ in water $(3.0 \mathrm{~mL})$ was added over $4 \mathrm{~h}$ using a syringe pump. The reaction was then poured onto water and partitioned between EtOAc and water and the combined organic phases were dried $\left(\mathrm{MgSO}_{4}\right)$, filtered and concentrated in vacuo. Purification by flash chromatography (12.5-25\% EtOAc/heptane) furnished triprotected pyranicin 84 as a clear oil (15.0 mg, 85\%): $[\alpha]_{\mathrm{D}}^{23}+19.4\left(\mathrm{c}=1.0, \mathrm{CH}_{2} \mathrm{Cl}_{2}\right)$; IR (film) 3399 (br, w), 2927 (s), 2856 (s), 1758 (m), 1461 (m), 1429 (m), 1089 (s), 1027 (m); ${ }^{1} \mathrm{H}$ NMR (500 MHz, $\mathrm{CDCl}_{3}$ ) $\delta 7.74-$ $7.62(\mathrm{~m}, 4 \mathrm{H}), 7.45-7.28(\mathrm{~m}, 6 \mathrm{H}), 7.13(\mathrm{~d}, J=1.3 \mathrm{~Hz}, 1 \mathrm{H}), 5.01(\mathrm{dq}, J=6.6,1.4 \mathrm{~Hz}, 1 \mathrm{H}), 3.70-$ $3.62(\mathrm{~m}, 2 \mathrm{H}), 3.62-3.55(\mathrm{~m}, 1 \mathrm{H}), 3.55-3.42(\mathrm{~m}, 3 \mathrm{H}), 3.29-3.23(\mathrm{~m}, 1 \mathrm{H}), 3.05(\mathrm{t}, J=6.6 \mathrm{~Hz}, 1 \mathrm{H})$, 2.49-2.36 (m, 3H), 1.88-1.61 (m, 3H), 1.60-0.73 (m, 44H), $1.41(\mathrm{~d}, J=6.8 \mathrm{~Hz}, 3 \mathrm{H}), 1.08(\mathrm{~s}, 9 \mathrm{H})$, $0.88(\mathrm{~s}, 9 \mathrm{H}), 0.08(\mathrm{~s}, 3 \mathrm{H}), 0.06$ (s, 3H), $0.00(\mathrm{~s}, 9 \mathrm{H}) ;{ }^{13} \mathrm{C} \mathrm{NMR}\left(125 \mathrm{MHz}, \mathrm{CDCl}_{3}\right) \delta$ 173.9, 151.3, 136.0, 135.9, 134.7, 134.2, 130.8, 129.4, 129.1, 128.0, 127.4, 127.3, 80.7, 80.4, 77.4, 76.6, 74.5, $71.9,67.7,66.3,37.6,37.4,34.1,32.2,31.9,29.87,29.83,29.69,29.63,29.5,29.3,27.1,25.9$, 25.8, 25.6, 25.5, 25.3, 22.6, 19.6, 19.1, 18.6, 14.1, -1.3, -4.2, -4.5; HRMS (FAB, M+Na+) calcd 
for $\mathrm{C}_{62} \mathrm{H}_{108} \mathrm{NaO}_{7} \mathrm{Si}_{3}$ 1071.7301, found 1071.7296; The product contained traces of tosylhydrazine.

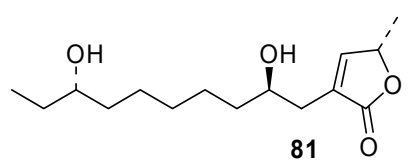

(S)-3-((2R,8S)-2,8-dihydroxydecyl)-5-methylfuran-2(5H)-one (81). Butenolide 81 was isolated along with 1 after the deprotection step, as a clear oil; $\left(3.0 \mathrm{mg}, 51 \%\right.$ over 3 steps): $[\alpha]_{\mathrm{D}}^{23}+17.9$ (c = 0.24, $\mathrm{CH}_{2} \mathrm{Cl}_{2}$ ); IR (film) 3419 (m, br), 2929 (s), 2856 (m), 1741 (s), 1459 (w), 1321 (w), $1079(\mathrm{w}), 1027(\mathrm{w}) ;{ }^{1} \mathrm{H} \mathrm{NMR}\left(500 \mathrm{MHz}, \mathrm{CDCl}_{3}\right) \delta 7.18(\mathrm{dd}, J=2.3,1.1 \mathrm{~Hz}, 1 \mathrm{H}), 5.06(\mathrm{dq}, J=$ 6.8, $1.4 \mathrm{~Hz}, 1 \mathrm{H}), 3.89-3.81(\mathrm{~m}, 1 \mathrm{H}), 3.57-3.45(\mathrm{~m}, 1 \mathrm{H}), 2.53(\mathrm{tdd}, J=15.1,3.0,1.3 \mathrm{~Hz}, 1 \mathrm{H}), 2.40$ (tdd, $J=15.3,8.3,1.1 \mathrm{~Hz}, 1 \mathrm{H}), 1.71(\mathrm{~s} \mathrm{br}, 2 \mathrm{H}), 1.58-1.19(\mathrm{~m}, 12 \mathrm{H}), 1.43(\mathrm{~d}, J=6.8 \mathrm{~Hz}, 3 \mathrm{H})$, $0.94(\mathrm{t}, J=7.2 \mathrm{~Hz}, 3 \mathrm{H}) ;{ }^{13} \mathrm{C} \mathrm{NMR}\left(125 \mathrm{MHz}, \mathrm{CDCl}_{3}\right) \delta 174.5,151.8,131.1,77.9,73.2,69.9$, 37.3, 36.8, 33.4, 30.2, 29.5, 25.5, 25.5, 19.1, 9.8; HRMS (FAB, $\mathrm{H}^{+}$) calcd for $\mathrm{C}_{15} \mathrm{H}_{27} \mathrm{O}_{4} 271.1909$, found 271.1905. 


\section{Determination of the relative configuration of the stereocenters of the THP-}

rings in 29 and 28

a) Preparation of, and analytical data for compound 87

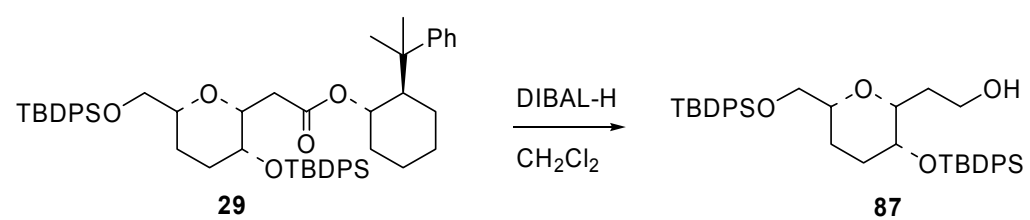

In order to confirm the stereochemical assignment of compound 29, it was converted to alcohol 87 by reduction with DIBAL-H; 87: ${ }^{1} \mathrm{H}$ NMR $\left(500 \mathrm{MHz}, \mathrm{C}_{6} \mathrm{D}_{6}\right) \delta$ 7.95-7.72 (m, 8H), 7.30-7.15 (m, 12H), $3.79(\mathrm{dd}, J=10.7,6.3 \mathrm{~Hz}, 1 \mathrm{H}), 3.75-3.67(\mathrm{~m}, 1 \mathrm{H}), 3.67-3.59(\mathrm{~m}, 2 \mathrm{H}), 3.52-$ $3.46(\mathrm{~m}, 1 \mathrm{H}), 3.42-3.33(\mathrm{~m}, 1 \mathrm{H}), 3.21-3.14(\mathrm{~m}, 1 \mathrm{H}), 2.36-2.20(\mathrm{~m}, 2 \mathrm{H}), 1.85(\mathrm{dq}, J=13.2,3.8$ Hz, 1H), 1.72-1.65 (m, 1H), 1.24-0.97 (m, 2H), 1.22 (s, 9H), 1.16 (s, 9H).

Diagnostic NOESY correlations of cis-cis THP 87:

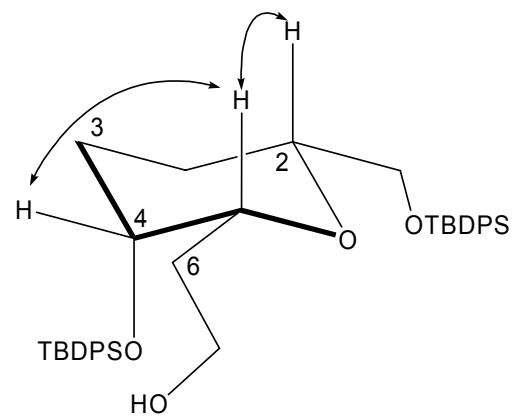




\section{b) Preparation of, and analytical data for compound 88}

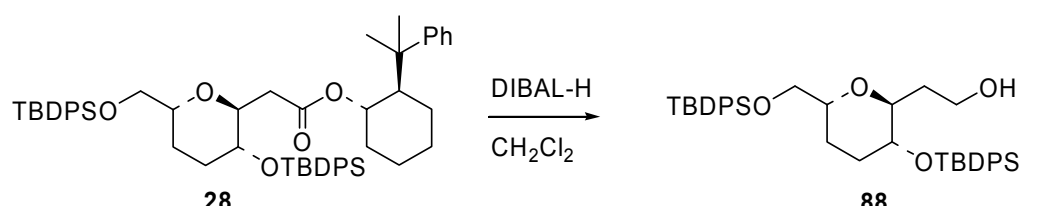

28

88

In order to confirm the stereochemical assignment of compound $\mathbf{2 8}$, it was converted to alcohol 88 by reduction with DIBAL-H; 88: ${ }^{1} \mathrm{H}$ NMR (500 MHz, $\left.\mathrm{C}_{6} \mathrm{D}_{6}\right) \delta$ 7.86-7.79 (m, 4H), 7.79-7.40 (m, 2H), 7.74-7.68 (m, 2H), 7.29-7.13 (m, 12H), $3.93(\mathrm{td}, J=10.5,3.6 \mathrm{~Hz}, 1 \mathrm{H}), 3.85(\mathrm{dd}, J=$ 10.4, $7.4 \mathrm{~Hz}, 1 \mathrm{H}), 3.75(\mathrm{qd}, J=11.6,3.9 \mathrm{~Hz}, 1 \mathrm{H}), 3.65(\mathrm{dd}, J=10.5,5.1 \mathrm{~Hz}, 2 \mathrm{H}), 3.56(\mathrm{dd}, J=$ $10.4,4.2 \mathrm{~Hz}, 1 \mathrm{H}), 3.51(\mathrm{td}, J=5.4,3.7 \mathrm{~Hz}, 1 \mathrm{H}), 2.60(\mathrm{t}, J=5.5 \mathrm{~Hz}, 1 \mathrm{H}), 1.78-1.67(\mathrm{~m}, 1 \mathrm{H}), 1.62-$ $1.48(\mathrm{~m}, 2 \mathrm{H}), 1.46-1.35(\mathrm{~m}, 1 \mathrm{H}), 1.22(\mathrm{~s}, 9 \mathrm{H}), 1.16(\mathrm{~s}, 9 \mathrm{H}), 1.10-0.98(\mathrm{~m}, 1 \mathrm{H})$.

Diagnostic NOESY correlations of trans-trans THP $\mathbf{8 8}$ :

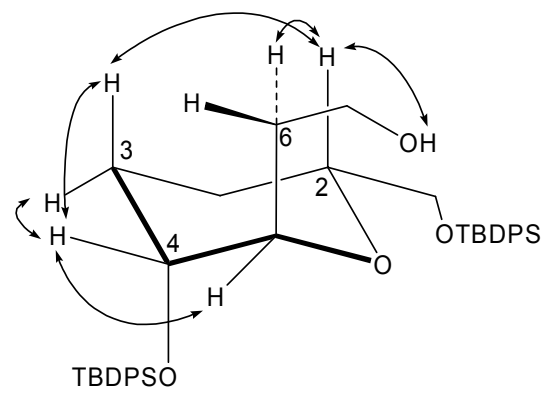




\section{Procedure for determination of $d r$ of the butenolide. ${ }^{16}$}

NMR spectra was recorded at $500 \mathrm{MHz}$ for ${ }^{1} \mathrm{H}$. To a sample of $\mathbf{8 1} 1^{17}(2.5 \mathrm{mg}, 0.036)$ in $\mathrm{CDCl}_{3}(1.2$ mL) was added (R)-2,2,2-trifluoro-1-(9-antryl)etanol in an NMR-tube. First 6.0 equiv and then 17.0 equiv. Spectra were recorded at $298 \mathrm{~K}$ and $223 \mathrm{~K}$ with and without irradiation at $\delta=1.41$ ppm (35 Db).

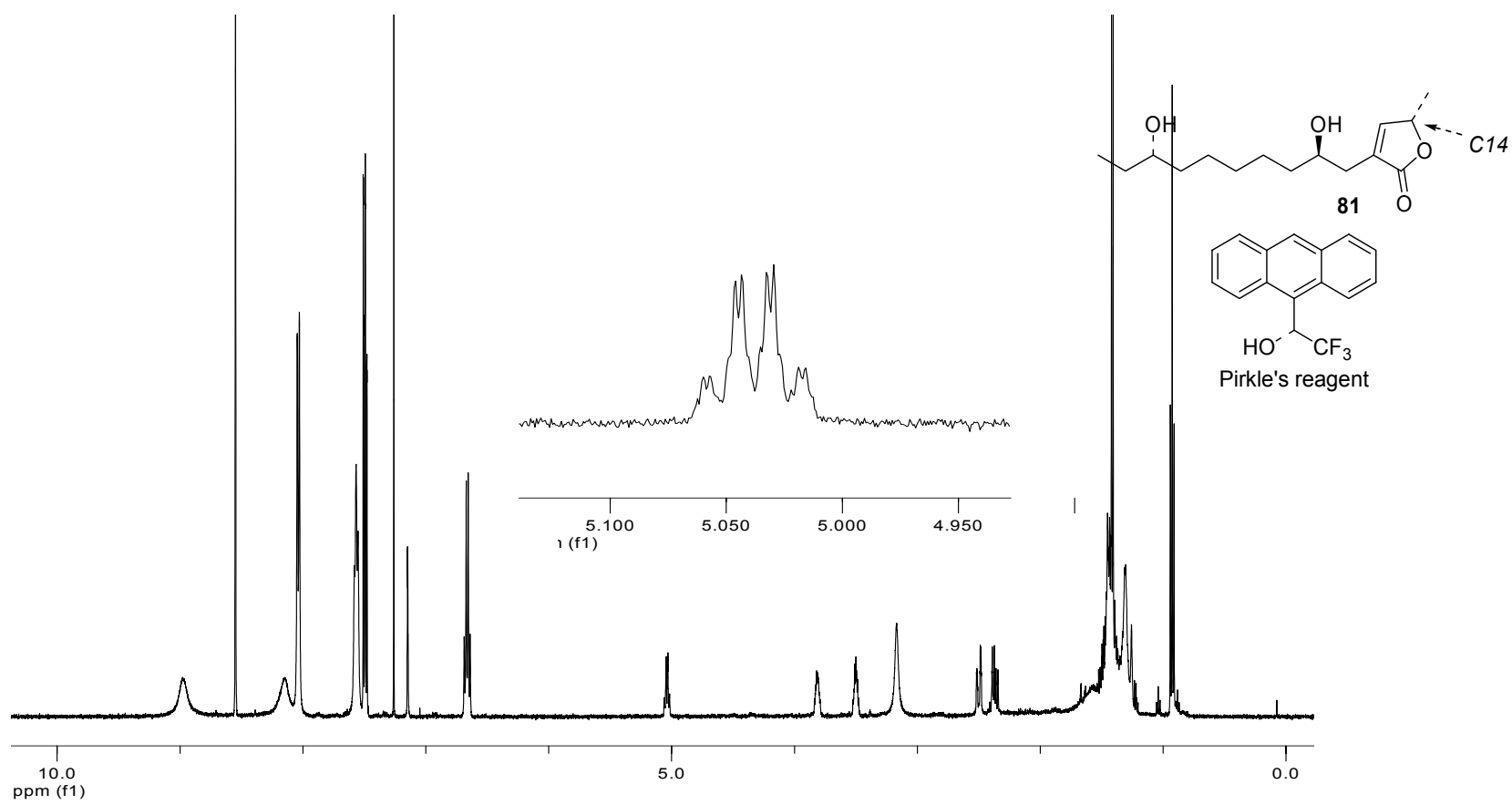

Figure 1. ${ }^{1} \mathrm{H}$ NMR of $\mathbf{8 1}$ at $298 \mathrm{~K}, 6$ equiv CSA, no irradiation. The magnification shows the signal from the $\mathrm{C} 14$ proton. 


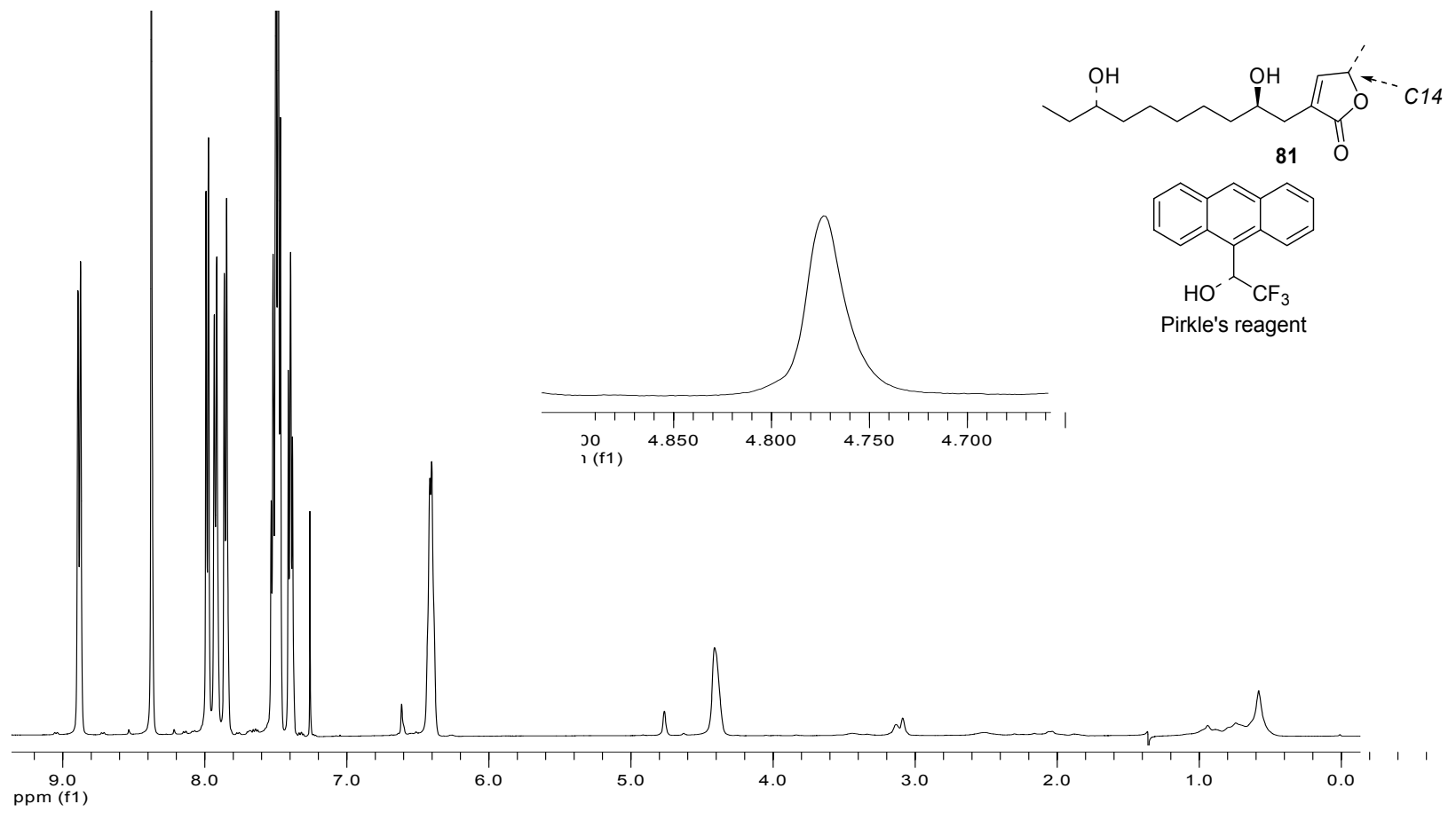

Figure 2. ${ }^{1} \mathrm{H}$ NMR of 81 at $223 \mathrm{~K}, 17$ equiv $\mathrm{CSA}$, irradiation at $\delta=1.41(35 \mathrm{Db})$. The magnification shows the signal from the $\mathrm{C} 14$ proton. ${ }^{18}$ 
${ }^{1}$ Ireland, R. E.; Meissner, R. S. J. Org. Chem. 1991, 56, 4566-4568.

${ }^{2}$ Still, W. C.; Kahn, M.; Mitra, A. J. Org. Chem. 1978, 43, 2923-2925.

${ }^{3}$ In addition, $224 \mathrm{mg}$ (12\%) of a mixture of primary and secondary alcohol was recovered. This mixture could be re-equilibrated under the following conditions: A mixture of primary alcohol $\mathbf{1 7}$ and secondary alcohol 18 was dissolved in EtOH followed by addition of catalytic amounts of DMAP. The resulting solution was refluxed for $14 \mathrm{~h}$ and then subjected to a similar workup as described above to give an additional $159 \mathrm{mg}$ ( $70 \%)$ of secondary alcohol, thus increasing the overall yield of $\mathbf{1 8}$.

${ }^{4}$ No signal attributed to a minor epimer at $\mathrm{C} 2$ could be detected by ${ }^{1} \mathrm{H}$ NMR. The diastereomeric ratio $(3 R, 6 R)-27:(3 S, 6 S)-27$ is $93: 7$, i.e. unchanged compared to the s.m.22. Note that 27 is not a diastereomer of $\mathbf{2 8}$, since the chiral auxiliary used in $\mathbf{2 7}$ is (-)-(1R,2S,5R)-8-phenylmenthyl, unlike that of $\mathbf{2 8}$ where $(1 S, 2 R)$-nor-8-phenylmentyl is used.

${ }^{5}$ A pre-heated oilbath was used since precise temperature control was critical to avoid byproduct formation.

${ }^{6}$ Prepared using an Arbuzov protocol similar to that used in: Nagata, W.; Wakabayashi, T.; Hayase, Y. Org. Synth. 1973, 53, 44-48.

${ }^{16}$ Latypov, S.; Franck, X.; Jullian, J.-C.; Hocquemiller, R.; Figadere, B. Chem. Eur. J. 2002, 8, $5662-5666$.

${ }^{17}$ We have found partial decomposition of annonaceous acetogenins when exposed to Pirkle's reagent for prologed periods which prompted us to use $\mathbf{8 1}$ instead of $\mathbf{2}$ for this study. This material was obtained in the same batch as $\mathbf{2}$ and has been exposed to the exact same conditions as $\mathbf{2}$ why it could be considered a good model to evaluate the stereochemical integrity of the C34 position of pyragonicin. 
${ }^{18}$ On the basis of ref. 13 , we would expect any $\mathrm{C} 14-(R)$ isomer present to give rise to a partially separated peak in the region 0.04 to $0.09 \mathrm{ppm}$ upfield from the $\mathrm{C} 14$ proton $(\delta=4.775)$ under these conditions. 